Article

\title{
Sustainable Change Management through Employee Readiness: Decision Support System Adoption in Technology-Intensive British E-Businesses
}

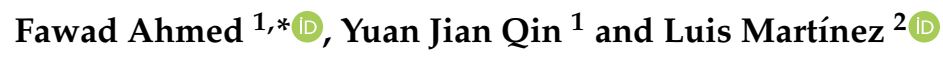 \\ 1 School of Management, Wuhan University of Technology, Wuhan 430070, China; qyjhb@163.com \\ 2 Department of Computer Sciences, University of Jaen, 23071 Jaen, Spain; martin@ujaen.es \\ * Correspondence: fawadahmed1@live.com
}

Received: 8 March 2019; Accepted: 21 May 2019; Published: 28 May 2019

check for updates

\begin{abstract}
Technology brings green sustainable management practices to the workplace. It is important to ascertain the factors that enable or inhibit employees' perceptions towards technology adoption. Corporate sustainability and sustainable management practices partially depend on employees for the successful implementation of technological changes in the workplace. This study aims at applying the technology acceptance model (TAM) from an employees' user-perspective. It addresses those factors that form employee readiness for e-business and enable their intention to use e-business technologies such as decision support systems (DSS). It focuses on technology intensive firms while combining Davis' technology acceptance model and Lai and Ong's employee readiness for e-business (EREB) model. A survey questionnaire was used to collect the data for this cross-sectional study from 331 employees of 28 well-established small and medium-sized e-businesses located in the United Kingdom. The outcomes show that the four dimensions of EREB explain the $58.2 \%$ of variance in perceived ease of use and the $50.2 \%$ of variance in perceived usefulness. Together, perceived usefulness and perceived ease of use explain the $51.8 \%$ of variance in intention to use while fully mediating the relationship between higher order EREB construct and intention to use DSS.
\end{abstract}

Keywords: employee readiness for e-business; decision support systems; TAM; perceived usefulness; intention to use

\section{Introduction}

Decision support systems (DSS) form part of the Internet of Things (IoT). IoT refers to a wide range of platforms, devices and technologies which are linked together on the world wide web (WWW); including varying communication patterns in different networks [1]. The idea of IoT is based on the interaction between a vast array of smart things or objects including, but not limited to, mobile phones, sensors, radio frequency identification (RFID) tags, actuators etc., in order to reach common goals via distinctive addressing schemes [2]. Therefore, DSS are essentially a part of IoT.

It was forecasted that IoT devices will be the largest category of connected devices in 2018 with 16 billion units [3]. The Internet is the infrastructure for IoT and WWW is the application that permits access to this infrastructure. DSS is one of the things in the IoT that operates through internal networks, analyzes data to generate reports, and communicates through the intranet as well as the Internet. IoT has numerous field applications, from tracking energy consumption to connecting software applications that optimize the traffic routes, enhancing fuel efficiency by reducing traffic jams [4] and extending assistance in biological studies [5].

E-business and the Internet of things (IoT) have enabled businesses to bring innovation to their processes. Schumpeter [6] defined an innovation as "something that reduces costs and increases quality 
and performance". So, adopting Internet based platforms and electronic commerce is primarily an innovative step for any organization. Firms have fallen victim to technological change, sometimes due to a paradigm shift. Kodak is one such example of failure during the transition period to digital cameras and related technologies. Moreover, numerous studies have tried to determine the factors influencing the acceptance of a new technology. The contexts of these studies range from customer's perspective, industry outlook to organizational context. However, employees' perspectives are somewhat lacking when it comes to academic research and literature with respect to technology acceptance at individual level.

Adopting modern technology is a matter of survival for e-business firms due to its impact on sustainable business development. Innovation in the workplace is vastly technology-driven in modern business models and depends on information systems [7]. Sustainability of a business model depends on its ability to adapt and to be flexible towards change, especially technological change in the current business environment. Sustainable management practices, during the continuous technological evolution in the workplace, are dependent on the core change agent i.e., employee behavior in response to such changes $[8,9]$. This rapid change in technological environment requires continuous change management practices in the workplace ensuring that employees are ready for the challenges in future [10]. E-business information systems have huge potential to bring sustainable business development [7]. Corporate sustainability is, in part, dependent on employees' collative use of new and evolving technologies [11]. Therefore, it is important to ascertain and research such factors that enable or inhibit employee perceptions about new technologies. Employee behavior is a key factor in enabling profitable and sustainable management practices. This study aims to contribute to this effect by studying factors that cause or inhibit employee readiness in order to enable better management of human capital, and to ensure sustainable corporate practices.

Existing literature focuses on understanding the reasons behind adoption and usage of technologies, which inherently means a paperless office. Moreover, the literature is mostly aimed towards sustainable business practices as part of corporate social responsibility (CSR) commitments [11]. Firms operating in competitive industries must concentrate on managing sustainable human capital proactively through methods other than conservative techniques for a positive impact on innovation capability.

Sustainable management practices require a focus on employees from a holistic point of view. Employees create relational wealth through partnerships with their employers built over time. There must be coordination and motivation among employees at operational as well as strategic levels to ensure that corporate sustainability goals are achieved. Management must make use of employee capabilities in order to be able to work towards the shared vision of corporate sustainability [12].

Bigi, Hamon-Cholet and Lanfranchi [13] studied information and communication technology (ICT) from the perspective of human sustainability during computerization in the workplace as well as from a management practice viewpoint related to organizational change. They found out that the human sustainability of ICT and management changes depends on whether or not institutional context is taken into account during the implementation phase for new technologies. Thus, an employee's role becomes vital in the institutional context.

This study mainly focuses on determinants of employee behavior towards technology use in e-business environments. The focus is narrowed down to DSS as the technology in question. DSS is, in essence, an application or software linked with one or more types of information systems. Moja, Passardi, Capobussi, Banzi, Ruggiero, Kwag, Liberati, Mangia, Kunnamo, Cinquini, Vespignani, Colamartini, Di Iorio, Massa, Gonzalez-Lorenzo, Bertizzolo, Nyberg, Grimshaw, Bonovas and Nanni [14] studied computer-based DSS linked to the health record systems of patients. Masum, Beh, Azad and Hoque [10] studied how human resource information systems (HRIS), when combined with knowledge discovery in database (KDD), perform the functions of DSS for structured, semi-structured and unstructured decisions related to human resources (HR). Thus, DSS may combine one or more features or software applications such as the web-based information system (WBIS), sales management information system (SMIS), customer relationship management system (CRMS), travel industry-specific 
global distribution systems (GDS), supply chain management (SCM) systems and online/e-payment systems integrated with each other. Such information systems may have varying levels of access to personnel as determined by the hierarchical levels. The ultimate purpose of these technologies is to help staff and managers make informed and accurate decisions about sustainable technological changes.

In the midst of this fast-paced change in technology, Big Data applications and collaboration initiatives between businesses, it is imperative for e-business managers to be skilled in acquiring information on market needs; analyzing such information systematically and making use of it in the development of novel goods and services [15]. It is also crucial that managers bring employees onboard by ensuring an infrastructure that keeps employees and the workforce up-to-date with technological use. This is where the decision support systems play a vital role as an assistive technology. The sustainability of all such initiatives still relies heavily on employee behavior and competitiveness for reporting and decision-making.

Although this study's respondents are employees, the hypotheses and conceptualization do not argue for a difference in outcomes for the core technology acceptance model (TAM). This study emphasizes employees as the users of technology; the difference between the employee and customer is that of the environment and the "choice". An employee does not have a choice, but a customer does. Therefore, the factor-independent variables in this study are such factors that relate to workplace and job-related issues. It is pertinent to mention that the individual users are inherently the same human beings; the only difference is the environment i.e., the workplace for employees as compared to the marketplace for customers. Table 1 shows how the management of an organization sees the customers and employees differently.

Table 1. Difference between employees and customers as users of technology.

\begin{tabular}{ll}
\hline \multicolumn{1}{c}{ Employees } & \multicolumn{1}{c}{ Customers } \\
\hline Employees are a resource (input) for the organizations & Customers are a source of revenue (part of output) \\
\hline $\begin{array}{l}\text { Employees do not have a choice to adopt or not to } \\
\text { adopt a new technology in the workplace }\end{array}$ & Customers may choose not to adopt a new technology \\
\hline $\begin{array}{l}\text { Employee's perceptions about a technology's } \\
\begin{array}{l}\text { usefulness relate to career growth and rewards } \\
\text { associated with it }\end{array}\end{array}$ & $\begin{array}{l}\text { Customers' perceived usefulness is related to utility } \\
\text { and optimizing satisfaction from the use of a new } \\
\text { technology }\end{array}$ \\
\hline
\end{tabular}

Sources: $[8,9,16-26]$.

Although in recent years there has been a plethora of studies on technology readiness and technology acceptance from the consumer's perspective, industrial context, or in the organizational adoption as a whole $[5,10,14,27-37]$, there is scarcity of research from an employee's perspective as the unit of analysis for readiness and technology acceptance $[11,36,38-42]$ in e-business environments. Moreover, no studies of such nature are found for technology intensive environments.

Therefore, the objectives of this research are threefold:

I The study of employee's behavioral intention to use DSS through TAM.

II To analyze whether the four reflective dimensions of employee readiness for e-business (EREB) i.e., Benefits, Security, Collaboration and Certainty in an e-business environment, have an impact on perceived usefulness and ease of use for DSS.

III To establish that the TAM model holds true for the employees as a user of high-end technologies under 'mandatory' technology use settings; as opposed to majority of past research which focuses on customers as users who have a choice to not use a given technology.

These objectives will provide an overall perspective on the managerial implications towards the identification of the role of these four dimensions in establishing positive behavioral intention to use DSS among employees for the successful roll out of new technologies in the work place. It shall support the management in proposing such measures that may help in the supervision of the four 
dimensions of EREB through appropriate managerial actions in order to successfully implement DSS. This study contributes in several ways. First, it combines and analyzes the relationship between two models i.e., EREB and TAM. Second, this study examines the behavior of employees as users and the relationship with perceptions of ease and usefulness. Third, it studies the resistance caused by employee concerns about job security, which may inhibit intention to use technologies such as DSS. Fourth, it shall contribute to existing literature by adding to the knowledgebase on the relationship of the constituent factors of employee readiness for e-business i.e., Benefits, Security, Certainty and Collaboration, with the perceived usefulness and perceived ease of use for DSS, which does not exist yet. Fifth, the individual user sample in our case is predominantly skilled in technology use and innovative to a certain extent because they are in technology-intensive environments where they would not be hired and employed unless and until they are considered technologically savvy; this is not the case in the majority of past studies in extant literature where users are rarely known to be technology-savvy and are not targeted from within a technology-intensive population.

Although it can be argued that employees or customers are both in fact individuals and the expected behavioral outcomes could be similar, this study is carried out in organizations where employees must use new technology in their general tasks; whereas customers are not bound to use technologies whenever they are introduced to them by an organization, they can choose to use them or not.

The remainder of the paper is structured as follows. Section 2 discusses the relevant concepts from the existing literature related to DSS, TAM, employee readiness for e-business, and change readiness. Section 3 explains the hypotheses, methodology and measures used in this study to analyze the data. Section 4 constitutes discussion on the measurement model, structural model and mediation results along with the model strength and quality. Section 5 elaborates the application and implications of the results of our study and presents relevant suggestions for managers and practitioners. Section 6 provides concluding remarks with limitations of this research and proposed future research.

\section{Literature Review}

Here, we will review concepts, technologies and models that should be presented to understand the underlying proposal of this paper.

\subsection{Decision Support Systems (DSS)}

Decision support systems are information technology-based software applications that present employees with specific, action-able suggestions or intelligently sifted management alternatives to help make suitable decisions [14]. With advances in technology, DSS are also evolving day by day. Sprague [43] was the first to properly define the term DSS; it aims to deal with less well-structured and underspecified problems faced by top-management. DSS try to carry out a combined usage of models or analytic techniques. They offer conventional functions for data access and retrieval. More specifically, DSS focus on such features that enable ease of use for less technology-conversant people in an interactive way. In addition, DSS are more flexible and adaptable to change.

Holsapple and Whinston [44] classified DSS into six main types of frameworks: text-oriented, database-oriented DSS, spreadsheet-oriented DSS, solver-oriented, rule-oriented, and compound DSS. A compound DSS is currently the most commonly used classification in organizations with a hybrid system that combines two or more of the five basic structures [45].

Burstein and Holsapple [46] identified DSSs that perform selected cognitive decision-making functions and are based on artificial intelligence (AI) which they called intelligent decision support systems (IDSS). IDSS are capable of making pre-programmed decisions in pre-defined situations, such as Supply chain management; medical diagnostic systems; expert systems for scheduling operations in manufacturing firms; agricultural productions system; fraud detection and mitigating transaction delays and web-based advisory systems, which are all based on intelligent systems [45]. Such IDSS are beyond the scope of this research as they are based on samples from firms utilizing compound DSS at 
an individual level in daily computerized environments to make decisions based on a given set of data, reports and options generated by DSS.

\subsection{E-Business Technologies and the Internet of Things (IoT)}

A growing integral issue in all technology intensive organizations is to effectively incorporate network and distributed information technology to integrate resources among organizations, vendors, employees, and suppliers. Lucas H, Goh J. [47] argues that information technology can create new digitally consumed products and related services and thus possesses the power to influence transformation across industries. Organizations are thus implementing electronic business (e-business) technologies and interfaces at an accelerating pace. However, over time even those firms that are considered e-businesses have to upgrade existing technology or introduce new technology every few years. This fuels speculation about the level of employee readiness to embrace this new type of firm that has to face frequent organizational changes stemming from technological advances.

A wide range of studies have been conducted to explore issues with respect to the readiness of organizations towards adoption of e-business, and useful managerial implications and solutions have been devised. However, they either lack solid theoretical frameworks or mostly focus on technology adoption from a customer perspective, organizational perspective or geographical viewpoint [41,42,48-57], as compared to a few studies which focus on employee readiness for e-technologies at an individual level $[8,41,48,58,59]$.

\subsection{Evolution of Technology Acceptance Model (TAM)}

The technology acceptance model (TAM) is the culmination of the underlying concepts of the Theory of Reasoned Action (TRA) and the Theory of Planned Behavior (TPB). Fishbein and Ajzen [60] developed the TRA which has proven to be one of the most frequently used models to study intention and is deemed suitable "to explain virtually any human behavior" [61]. The theory states that a specific behavior's actual execution is preceded by an individual's behavioral intention. Although it originated in social psychology, the generic nature of this model has made it successfully applicable to a diverse range of varying domains [62]. This intention is formed by constructs referred to as attitude and subjective norm. Attitude is "an individual's positive or negative feelings (evaluative affect) about performing the target behavior" [60]. TRA had a limitation that it did not consider the underlying possibility of unavailability of resources or simply the lack of opportunity for the individuals to perform an intended behavior. Keeping in mind that only the intention may prove insufficient as a predictor of individual action, reference [61] TRA further developed into TPB. The notion that "behavioral achievement depends jointly on motivation (intention) and ability (behavioral control)" was propagated [60].

TAM caters for the individual's perceptions from both ease of use i.e., perceived behavioral control, as well as perceived usefulness. TAM has four key variables, two of which are adopted from TRA and TPB; perceived usefulness (PU), perceived ease of use (PEU), attitude towards use (ATU) and behavioral intention to use (IU).

\subsection{Employee Readiness for E-Business (EREB) Model-Predicting Employee Perceptions}

The focus of this study is on the level of an employee's readiness for e-business (EREB) as the predictor of employee perceptions of ease and usefulness of DSS leading to intention to use; it includes four dimensions i.e., Benefits, Collaboration, Security and Certainty [18].

Benefits (B): this dimension states that employees believe that benefits of e-business would include better productivity and improved efficiency. It would be helpful for them at work; employees always utilize functions provided by e-business and it enables them to be more competitive in their jobs.

Security (S) refers to the state of mind of an employee regarding job security. The employee does not worry about losing the job, changing the job, losing their influence or losing their power in the work environment. 
Collaboration $(\mathrm{C})$ is the readiness of employees "for interaction with each other, knowledge-sharing, working with their peers in a team and provide advice and extend a helping hand to co-workers in using e-business technologies" [18].

Certainty $(\mathrm{T})$ refers to the clarity in employees' minds regarding the purposes of e-business and the function of technologies involved in electronic business activities. Moreover, the employee believes that their organization has the capacity for the successful implementation of e-business technologies. In other words, certainty here refers to the 'trust' employees have in the management.

\section{Material and Methods}

\subsection{Hypotheses and Research Model}

Integrating the literature and hypotheses described below, the research model given in Figure 1 is adapted from [18] and [62]-a slight modification from the originally proposed conceptual model by [63] wherein "actual use" has been replaced by "intention to use" because the extant literature shows intention is always a precursor of actual use [64-66].

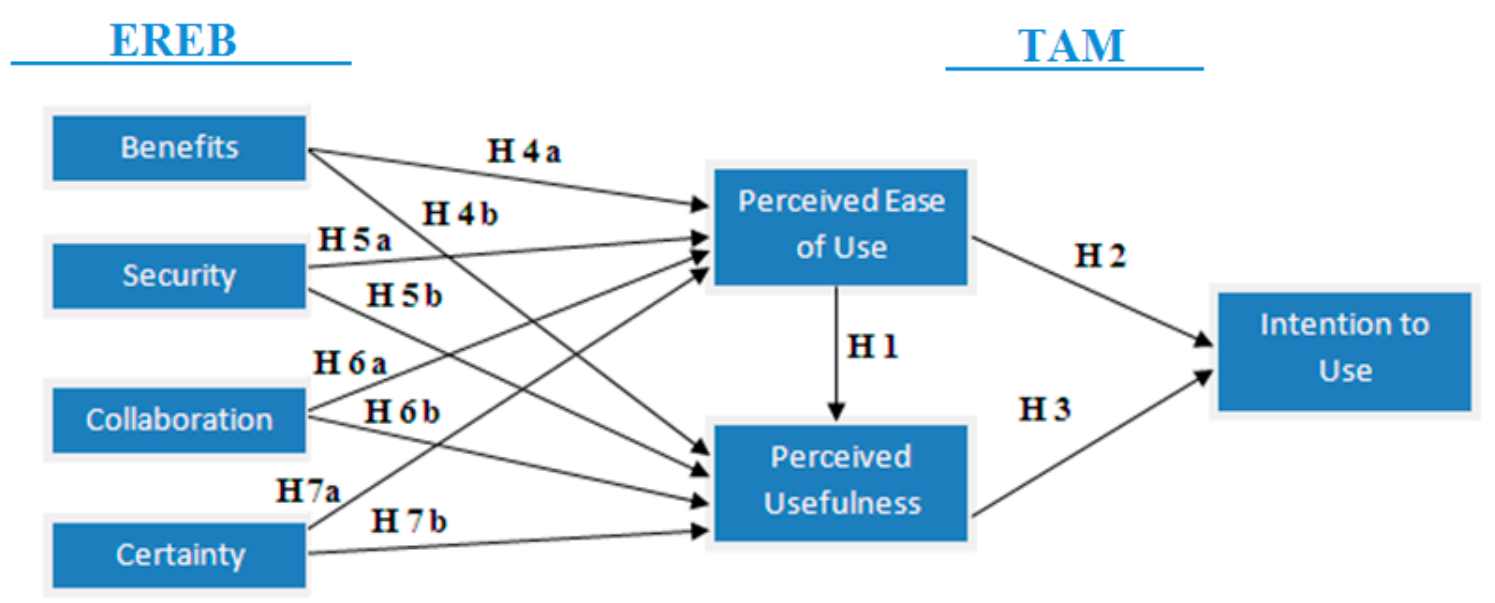

Figure 1. Conceptual model.

\subsubsection{Perceived Usefulness (PU), Ease of Use (PEU) and Intention to Use (IU)}

PU is an individual's prejudiced likelihood of usage of any given new technology subject to their belief of whether the technology in question shall lead to them improving their performance at work. So, in an organizational setting, PU is the likelihood of incremental productive capacity expected to result from the use of a new technology. PEU, as the construct's name indicates, is the degree of ease of using a particular technology, whether it is free of effort or if a minimal effort is required to use the target technology. The lesser the effort required, the higher the perceived ease of use. PEU is simply the potential user's anticipation of the new technology being free of effort in usage [67].

TAM has stood the test of time for user acceptance prediction. It stands out as a vigorous as well as the Parsimonious model, especially in information system studies [68]. The findings of TAM have been upheld time and again by a large number of researchers through varying experiments, applications, validations and replications [67].

The primary narrative of TAM is that an individual's internal convictions, with respect to ease of use and usefulness of any given technology, are the deciding factors in actual usage. PU has been studied as a potential customer's subjective opinion about the utility of a specific technology, which in turn possibly leads to fulfill individual objectives [62]. PEU is included as an exogenous variable which has an indirect affect on attitude towards use or intention to use via PU, which has proven in numerous studies to have a direct affect on attitude and is a direct determinant of continued information systems IS usage intentions $[49,69]$. This study hypothesizes a significant path from PEU to PU and from PEU to IU. Intention to use a DSS is modeled as a resulting construct predicted by PU and PEU. 
Social science research as well as information system research has uncritically affirmed that intention to use technology always leads to actual use [64-66]. It has been well-established that intention is the predictor of behavior [70]. Similarly [61] states "intention is the immediate determinant of behavior". Therefore, we shall also use IU as signifier of actual use. Thus, the following hypotheses are proposed:

Hypothesis 1 (H1). Perceived ease of use (PEU) of DSS will be positively related to its perceived usefulness (PU).

Hypothesis 2 (H2). Perceived ease of use (PEU) of DSS will be positively related to intention to use (IU).

Hypothesis 3 (H3). Perceived usefulness (PU) of DSS will be positively related to intention to use (IU) it.

\subsubsection{Benefits}

Benefits here means all such positive outcomes that an employee could perceive to result from the use of any given technology. It includes employee's beliefs that e-business and related technologies can lead to improvements in productivity, efficiency, speed, and an overall ease in their daily job performance. The employees positively consider the utility of the functions of e-business and related technologies and this positive belief enables them more competitive in their jobs [18], thus creating self-efficacy. Prior research on technology and information systems has proven a positive relationship between self-efficacy and PEU [67]. Benefits of e-business and DSS are the motivating factors for employees, similar to that which has been established in expectancy theory [71]. The supposition of association of behavior with a certain anticipated outcome is the point of focus. Employees may have an expectation of certain benefits if they adopt and use DSS.

Atkin, Chaudhry, Chaudry, Khandelwal and Verhoogen [72] invented a new cutting edge technology that reduces waste of the primary raw material and gives the technology a random subset of producers. Despite the clear net benefits for nearly all firms, after 15 months the rate of take-up remained puzzlingly low. They hypothesized that an important reason for the lack of adoption is a misalignment of incentives within firms. The key employees (cutters and printers) are typically paid piece rates, with no incentive to reduce waste, and the new technology slows them down, at least initially. Fearing reductions in their effective wage, employees resist adoption because it reduces their benefits.

Benefits could either be extrinsic or intrinsic. Extrinsic motivation involves a perceived contingency between specific behaviours and desirable consequences such as tangible incentives [39]. WhereasKuvaas, Buch, Weibel, Dysvik and Nerstad [73] elaborate that apart from the aim to enhance performance, the role played by intrinsic motivation in energizing a variety of productive behaviours cannot be ignored. This affects both the emotions as well as attitudes resulting in the reward of the experience of autonomy and also proves a causal effect in successful implementation.

Expectancy theory [71] is a suitable approach to understand human motivation. It focuses more on outward behavior than on internal needs, on the assumption that individual behavior is associated with certain outcomes. People may expect that if they accomplish certain tasks, they will receive certain benefits. It has been found that intrinsic motivation has positive associations with optimism [73]. Employees' perceived usefulness and perceived ease of use are factors that are affected by the expected benefits or loss of benefits brought by new technologies. Thus, it is expected that the higher perceived benefits of using DSS facilitates employees' PEU as well as PU:

Hypothesis 4a (H4a). Benefits of DSS will be positively related to its perceived ease of use (PEU).

Hypothesis $4 \mathbf{b}(\mathbf{H} 4 \mathbf{b})$. Benefits of DSS will be positively related to its perceived usefulness (PU). 


\subsubsection{Security}

Security refers to the state of mind of an employee regarding job security, whether they worry about losing their job, changing their job or even losing influence or power in their work environment [18]. It also includes their emotions and their mental states such as fear, apprehension and frustration. Anxiety related to computing work has been found in technology research to impose a significant negative effect on PEU [67]. It is only natural for some individuals to present a negative affective reaction towards an advanced and modern decision support system, which in turn shall likely exert an untoward influence on the perceived usefulness and ease of use of the system.

Job insecurity is negatively related to work-related outcomes [74]. Technology adoption and employee perceptions of ease and usefulness are job-related outcomes. On the other hand, positive dispositions towards their job would help employees build suitable expectations with the new system and they shall consequently use the system for a greater duration of time, with higher intensity, and more frequently [75]. Nam [76] studied employee attitudes to technology adoption and found that their current perceptions about job insecurity are strongly related to use of technology. It has been observed that job insecurity is also associated with organizational changes, role ambiguity and the receipt of information about organizational issues [77]. Technology brings change and thus it is associated with job security amongst employees.

Previous studies have shown that job insecurity leads to a withdrawal response and has a detrimental effect on employees' job performance and affective commitment [78-82].Better security and stability assists employees to perceive the implementation of a new system as a change that improves productivity, leading to a positive set of expectations from the system and a positive attitude toward the system [75].

In this study, Security is adopted as part of the EREB model by [18] and it refers to employees' concerns about the possibility of losing their job or the change of a job role or of loss of influence or power at the work place [83], which includes frustration, apprehension and fear.Thus, the following is expected:

Hypothesis 5a (H5a). Security concerns of using a DSS will have a negative effect on perceived ease of use (PEU).

Hypothesis $\mathbf{5 b}(\mathbf{H} 5 \mathbf{b})$. Security concerns of using a DSS will have a negative effect on perceived usefulness (PU).

\subsubsection{Collaboration}

Lai, Kan and Ulhas [9] argue that user participation not only improves communication and enables better utilization of information but also enhances the job skills and understanding of employees. The benefits of participation are attributed to greater trust, greater feelings of control, greater identification with the organization, and higher goals. Eventually, it enhances trust and contributes to a sense of ownership and control, improving system acceptance and commitment. Upon motivation and active participation, employees reduce resistance to change and enhance acceptance of and commitment to decisions and changes $[84,85]$. The more the employees participate in e-business activities, the more organizational e-business readiness there would be.

"User participation not only improves communication and enables better utilization of information but also enhances the job skills and understanding of employees" [9]. The relationship between collaboration and use of e-business technology has already been proven from an intra-organizational perspective [86]. Collaboration in technology adoption research has been studied as a construct revolving around the social influence and subjective norms aspects of technology use [70].

Previous findings suggest a close association between the technical characteristics of collaborative technologies and their implementation, adoption and assimilation in organizations [41]. Once collaborative technologies are in place, researchers address the human factors in terms of individual trust, cognition and attitude involved in computer-mediated communication from the user perspective [87]. Various 
psychological constructs and frameworks are employed to study technology-enabled collaboration in different settings, such as semi-virtual collaboration and hybrid team collaboration [84]. The emergence of geographic information systems (GIS) and related corporate operations (e.g., green supply chains), however, poses new challenges for the research of IT-enabled collaboration. An exploratory case study suggests that organizations need to integrate IT resources, employee effort and supply chain for the development of sustainability capabilities [88].

Technology adoption is not a one-man job. It takes the whole workforce to join hands in order to implement new initiatives. Where technology use during daily job tasks is a primary concern, it is even more important for organizations to have a workforce that collaborates for quick learning and adoption [11,86,89]. As observed by Agarwal and Karahanna [90], in any given technology's usage, frequency and acceptance can be improved during the initial mandatory usage stage of its launch in the workplace settings. This is only possible through employee participation and collaboration which eventually "enhances trust and contributes to a sense of ownership and control, improving system acceptance and commitment" [9]. Therefore, the following is proposed:

Hypothesis 6a (H6a). Collaboration has a positive relationship with perceived ease of use (PEU) of DSS.

Hypothesis $\mathbf{6 b}$ (H6b). Collaboration has a positive relationship with perceived usefulness (PU) of DSS.

\subsubsection{Certainty}

When the management provides support to individuals in the workplace, such as training sessions, guidance and counseling, it can enhance their ability to use any new technology depending on the level and extent of such support [89,91-94]. Thus, certain situational factors, such as institutional support, can prove significant in determining an employee's attitude and certainty toward the systems. Employees will feel more certain if the level of such support by management is increased, thus resulting in perceived certainty of the implementation of technology in an employee's mind, and enhancing the system PEU and PU [95].

Abdinnour-Helm, Lengnick-Hall and Lengnick-Hall [96] showed that allowing users sufficient discussion can reduce uncertainty and increase trust when implementing an enterprise resource planning (ERP) system, thereby enhancing organizational readiness. The more fears and concerns employees have, the less prepared they are to embrace e-business, implying that trust can lead to e-business readiness.

Certainty and trust are supposed to contribute to employees' perceived e-business benefits due to the reduced time and effort necessary for job tasks, as e-business can provide applications that enable employees to concentrate on more value-added job tasks, rather than double-checking errors on reports; or verifying the correctness of sales and purchase orders; worrying about the security and confidentiality of data and being concerned about system crashes $[9,97,98]$.

Phong, Hui and Son [99] conducted research involving 368 employees as respondents from 63 Chinese firms and the results showed that employee's trust in leaders is related to participative behavior. Thus, if the employees trust their employer, they will perceive new technology to be useful as well as easy to use.

Hypothesis 7a (H7a). Certainty for using a DSS will have a positive relationship with its perceived ease of use (PEU).

Hypothesis $7 \mathbf{b}(\mathbf{H 7 b})$. Certainty for using a DSS will have a positive relationship with its perceived usefulness (PU).

\subsection{Methodology}

As of December 2017, 5687 (99\%) of businesses in the United Kingdom were micro, small or medium-sized businesses (0-249 employees) and account for $60 \%$ of the total employed workforce. 
Out of these, 5445 (95\%) of businesses employed less than 10 people, these are called micro-sized businesses; 242 (5\%) of businesses employed 10 to 249 employees and these are called small and medium-sized enterprises and account for $27 \%$ of the UKs employed workforce [100].

Table 2 provides the demographics of the respondents and descriptive statistics. For the purpose of this study, data were collected from employees of small and medium-sized companies that employed more than 10 people and were essentially categorized as e-businesses. The primary reason for this was that micro businesses usually do not frequently change technology used in the workplace, nor is the technology used as advanced comparative to small and medium-sized enterprises. The authors searched the website of United Kingdom's official registration authority "Companies House" to identify 50 small and medium-sized enterprises (SMEs). The management of each of these companies was contacted and the purpose of our study was explained to them with a request for cooperation in data collection. A total of 28 businesses eventually participated in the study. All the companies were incorporated in the UK.

Table 2. Demographics and descriptive statistics.

\begin{tabular}{|c|c|c|}
\hline & Freq. & $\%$ Age \\
\hline \multicolumn{3}{|l|}{ Gender } \\
\hline Male & 204 & $61.63 \%$ \\
\hline Female & 127 & $38.37 \%$ \\
\hline \multicolumn{3}{|l|}{ Age (Years) } \\
\hline $20-29$ & 37 & $11.18 \%$ \\
\hline $30-39$ & 175 & $52.87 \%$ \\
\hline $40-49$ & 95 & $28.70 \%$ \\
\hline $50-59$ & 19 & $5.74 \%$ \\
\hline $60 \&$ above & 5 & $1.51 \%$ \\
\hline \multicolumn{3}{|l|}{ Experience (Years) } \\
\hline 01 to 02 & 67 & $20.24 \%$ \\
\hline 03 to 05 & 151 & $45.62 \%$ \\
\hline 06 to 08 & 63 & $19.03 \%$ \\
\hline 09 to 10 & 19 & $5.74 \%$ \\
\hline More than 10 & 31 & $9.37 \%$ \\
\hline \multicolumn{3}{|l|}{ Education } \\
\hline High School & 44 & $13.29 \%$ \\
\hline Bachelor Degree & 179 & $54.08 \%$ \\
\hline Master Degree & 108 & $32.63 \%$ \\
\hline \multicolumn{3}{|l|}{ Designation } \\
\hline CEO/G.M/M.D & 6 & $1.8 \%$ \\
\hline Manager & 23 & $6.9 \%$ \\
\hline Assistant Manager & 49 & $14.8 \%$ \\
\hline Senior Officer & 108 & $32.6 \%$ \\
\hline Officer & 122 & $36.9 \%$ \\
\hline Clerk & 23 & $6.9 \%$ \\
\hline
\end{tabular}

The respondents were employees who had already been using internet communication technologies and some form of office support software such as DSS, enterprise resource planning (ERP), management information systems (MIS), executive information systems (EIS), supply chain management (SCM), web-based systems (WBS) and customer relationship management systems (CRMS). Hence, we conclude that all respondents were skilled in technology use and had undergone a change process with the introduction of new application software at some stage of their careers.

A total of 692 questionnaires were sent out and 336 were returned, thereby yielding a total response rate of $48.6 \%$. After checking data for missing values, outliers and unusable responses, eventually, 331 responses remained usable, yielding an effective response rate of $47.8 \%$. The sample size of 331 in 
our study is considered appropriate keeping in line with the widespread application of the "10times rule of thumb" which has recommended minimum sample size to exceed ten times the number of independent variables [101].

Furthermore, from the point of view of "maximum number of arrows pointing at a latent variable", in our case, it was 4 arrows, which has a corresponding minimal sample size requirement of 65 [102-104]. In addition, as recommended by [105] from a statistical power analysis point of view during use of partial least square PLS method, if the outer and inner models have maximum of five independent variables, "one would need ninety-one observations to achieve a statistical power of 80 percent, assuming a medium effect size and a 5 percent a-level" $[102,103,106]$. The sample size of 331 used in our study substantially exceeds all the above criteria.

Respondents belonged to varying business sectors such as banking/financial services $(n=43)$, Fast moving consumer goods (FMCG) $(n=25)$, hospitality, travel and leisure $(n=126)$, IT/SEO/web services $(n=91)$, and telecoms/call centers/business process outsourcing $(B P O)$ sector $(n=46)$. There were 97 respondents from Greater London, 62 from Birmingham, 55 from Edinburgh, 31 from Glasgow and 86 from Manchester. Over $79 \%$ of the respondents had at least 3 years' experience. Over $86 \%$ of the respondents had at least a bachelor's degree.

As displayed in Table 3, the questionnaire included some questions to determine the types of information systems the respondents were familiar with in a workplace usage context. Although the information systems were identified by varying names, all of these mechanisms are by default synonymous with the definition of DSS because their collective purpose is report generation for decision-making. Moreover, just over $37 \%$ of respondents actually used the term DSS for the information systems used in work settings. Respondents were also asked if there was a different level of access and authority for DSS with the hierarchical levels: 69\% responded yes, while over $73 \%$ responded that their work involved using two or more software systems interlinked at some stage of the work process flow. Therefore, we were led to conclude that the sample used was a true representation of technology intensive environments in e-business settings.

Table 3. Technology intensiveness of respondents' employer organization.

\begin{tabular}{ccc}
\hline Types of Information Systems Used & Freq. & \%Age \\
\hline Global Distribution System (GDS) for Reservations & 126 & $38 \%$ \\
Management/Executive Information Systems (MIS/EIS) & 198 & $60 \%$ \\
Sage Pay or similar E-Payment Platform & 126 & $38 \%$ \\
Enterprise Resource Planning (ERP) software & 253 & $76.44 \%$ \\
Customer Relationship Management (CRM) Software & 278 & $83.99 \%$ \\
Decision Support System (DSS) & 123 & $37.16 \%$ \\
\hline Are any two or more software applications inter-linked for Decision-Making by Managers and for Reporting purposes? \\
Yes & 243 & $73.41 \%$ \\
No & 88 & $26.59 \%$ \\
\hline Is there a difference in level of access to information for employees, middle managers and top management? & 229 & $69 \%$ \\
Yes & 102 & $31 \%$ \\
\hline
\end{tabular}

\subsubsection{Measures}

Measurement tools from several previous studies were adapted for this study to ensure that the tools and instruments being used do not have any validity or reliability issues. The current questionnaire is adapted from several different questionnaires and questions were modified for the purpose of this study. The questionnaire used for data collection was divided into two main parts: demographic questions and the other part consisted of items related to each of the constructs in the model. Respondents were given clarification that the term Decision Support System includes all such information systems generally recognized as MIS, ERP, EIS or DSS but with report generation and analysis for decision-making purposes. 
The survey instruments used in this study was based on and modified from the TAM by [107] and EREB by [18]. There were 31 items in total. The original employee readiness for e-business scale by [18] consists of 18 items divided into four dimensions: Benefit (05 items) measured with items such as "Software, computers and related technologies such as decision support systems improve productivity for me."; Security (04 items) which was measured through statements such as "I am not threatened that technologies like decision support systems will result in a job change for me", Collaboration (04 items) with the example statement "I am happy to provide advice and help to fellow employees on how to use MIS, ERP, EIS or DSS and related technologies" and Certainty (05 items) with the example statement "I believe that my company can implement the adoption of new software and related technologies successfully". perceived ease of use, perceived usefulness and intention to use were measured through statements modified from [62] and [67] with five statements for PEU and PU respectively, and 3 statements for IU. A 7-point Likert scale was used and all measures were the self-assessment type. The questionnaire explained the objectives of study, assured confidentiality and anonymity of respondents and the voluntary nature of participation with a disclosure statement. All acronyms used in the questionnaire were described at the start of the questionnaire.

\subsubsection{Non-Response Bias and Common Method Bias}

Although the study received sufficiently high responses, the authors still made an assessment for any potential non-response bias. Early and late responses were tested by splitting the sample into two halves on the basis of response rate. The data collection period was 4 weeks and 2 days. The respondents who sent responses in the last 7 days $(n=113)$ were grouped as late responders and the rest $(n=218)$ were grouped as early responders. This analysis included one random selection of an indicator from each construct. No significant statistical differences were found between the two groups when the Mann-Whitney U-tests were performed $(p<0.05)$.

The authors also made an effort to contact the non-responding firms to enquire as to their reasons for non-participation. The companies mentioned two major reasons for non-participation, one that there was not sufficient time available to complete the survey, second that it was a simple matter of policy at those firms not to participate in such surveys for numerous reasons such as the increasing number of such requests from academic researchers. Moreover, "research has shown that the bias produced by PLS-SEM when estimating data from common factor model populations is low in absolute terms" [108].

\section{Results}

SmartPLS 3.2.7 (Boenningstedt, Germany) [109] and IBM SPSS Statistics 22 (Armonk, NY, USA) were used in this study. However, data analysis was conducted using smartPLS primarily because PLS-SEM is a preferred option due to its better predictive power over factor-based SEM [109]. Choosing PLS was encouraged over other CB-SEM softwares because smart-PLS can simultaneously estimate relationships between several independent as well as dependent variables in a structural model and multiple latent observed or unobserved variables in a measurement model [110].

Furthermore, PLS is believed to be a preferable approach for decision-making and management-oriented problems; it is also preferred when the study focuses on prediction [9]. In addition, PLS is the best choice in situations where other methods fail to converge; or when developed solutions are inadmissible. This holds true regardless of whether a common factor or composite model data is used $[108,111]$. Moreover, normality is required, and is a critical assumption of CB-SEM based software. Normality was a problem in our data when the Shapiro-Wilk test was conducted to find out if our data departed from normal distribution. Therefore, PLS was a preferred option because PLS can deal with skewed data and multi-colinearity issues more robustly [101]. 


\subsection{Measurement Model}

The assessment of the measurement model was carried out using the reliability and validity of the reflective indicators. The internal consistency reliability was established using composite reliability (CR) which has been recommended by scholars as being a better representative measure for reliability as compared to earlier practices that use Cronbach's alpha, as PLS does not require all indicators to have equal reliability [112], which is a limitation in other softwares.

Although the majority of the items displayed outer loading of above 0.70 to ascertain the reliability of latent variables, some weaker indicators with loadings between 0.460 and 0.69 were retained because of their contribution to content validity [113]. Keeping in mind that the minimum level of 0.40 is an acceptable value for item loading [107], none of the items had to be removed because all loadings were above 0.40 . Moreover, all the constructs showed high composite reliability scores of above 0.8 . Table 4 shows that the values ranged between 0.832 and 0.889 , thus confirming sufficient reliability [112].

Table 4. Item loadings.

\begin{tabular}{|c|c|c|c|c|c|c|c|c|}
\hline \multirow[b]{2}{*}{ Constructs } & \multirow[t]{2}{*}{ ITEM } & \multicolumn{7}{|c|}{ LOADINGS } \\
\hline & & BEN & COL & SEC & CERT & PEU & PU & IU \\
\hline \multirow{5}{*}{ Benefits (BEN) } & B1 & 0.830 & & & & & & \\
\hline & B2 & 0.652 & & & & & & \\
\hline & B3 & 0.537 & & & & & & \\
\hline & B4 & 0.658 & & & & & & \\
\hline & B5 & 0.827 & & & & & & \\
\hline \multirow{4}{*}{$\begin{array}{l}\text { Collaboration } \\
\quad(\mathrm{COL})\end{array}$} & $\mathrm{C} 1$ & & 0.769 & & & & & \\
\hline & $\mathrm{C} 2$ & & 0.808 & & & & & \\
\hline & $\mathrm{C} 3$ & & 0.840 & & & & & \\
\hline & $\mathrm{C} 4$ & & 0.766 & & & & & \\
\hline \multirow{4}{*}{ Security (SEC) } & $\mathrm{S} 1$ & & & 0.905 & & & & \\
\hline & $\mathrm{S} 2$ & & & 0.460 & & & & \\
\hline & S3 & & & 0.892 & & & & \\
\hline & $\mathrm{S} 4$ & & & 0.699 & & & & \\
\hline \multirow{5}{*}{$\begin{array}{c}\text { Certainty } \\
\text { (CERT) }\end{array}$} & $\mathrm{T} 1$ & & & & 0.658 & & & \\
\hline & $\mathrm{T} 2$ & & & & 0.704 & & & \\
\hline & T3 & & & & 0.874 & & & \\
\hline & $\mathrm{T} 4$ & & & & 0.729 & & & \\
\hline & $\mathrm{T} 5$ & & & & 0.603 & & & \\
\hline \multirow{5}{*}{$\begin{array}{l}\text { Perceived Ease } \\
\text { of Use (PEU) }\end{array}$} & PEU1 & & & & & 0.799 & & \\
\hline & PEU2 & & & & & 0.713 & & \\
\hline & PEU3 & & & & & 0.894 & & \\
\hline & PEU4 & & & & & 0.713 & & \\
\hline & PEU5 & & & & & 0.750 & & \\
\hline \multirow{5}{*}{$\begin{array}{l}\text { Perceived } \\
\text { Usefulness } \\
\text { (PU) }\end{array}$} & PU1 & & & & & & 0.734 & \\
\hline & PU2 & & & & & & 0.782 & \\
\hline & PU3 & & & & & & 0.744 & \\
\hline & PU4 & & & & & & 0.542 & \\
\hline & PU5 & & & & & & 0.728 & \\
\hline \multirow{3}{*}{$\begin{array}{l}\text { Intention to } \\
\text { Use (IU) }\end{array}$} & IU1 & & & & & & & 0.773 \\
\hline & IU2 & & & & & & & 0.912 \\
\hline & IU3 & & & & & & & 0.871 \\
\hline
\end{tabular}

To assess the construct validity by examining both the convergent and discriminant validity, suggestions by [113] were followed and 0.5 or higher was set as the acceptable value of average variance extracted (AVE) [114]. Table 5 shows that all the constructs had AVE values greater than 0.5 
and ranged between 0.504 and 0.729 , thus confirming convergent validity $[115,116]$. We assessed the discriminant validity using both Fornell-Larcker and Heterotrait-Monotrait (HTMT) criteria [111].

Table 5. Reliability and convergent validity.

\begin{tabular}{ccccc}
\hline & Cronbach's Alpha & RhoA & C.R & AVE \\
\hline BEN & 0.757 & 0.788 & 0.832 & 0.504 \\
CERT & 0.762 & 0.798 & 0.841 & 0.518 \\
COL & 0.806 & 0.806 & 0.874 & 0.634 \\
IU & 0.813 & 0.831 & 0.889 & 0.729 \\
PEU & 0.833 & 0.839 & 0.883 & 0.604 \\
PU & 0.750 & 0.763 & 0.834 & 0.505 \\
SEC & 0.726 & 0.769 & 0.838 & 0.579 \\
\hline
\end{tabular}

Fornell-Larcker criterion and the examination of cross-loadings are the "dominant approaches for evaluating discriminant validity ... and do not reliably detect the lack of discriminant validity" $[111,116]$. It was, therefore, decided to additionally report the Heterotrait-Monotrait (HTMT) ratio of correlations given in Table 6 below. Square roots of AVE values are shown in italics at diagonal.

Table 6. Discriminant validity: Fornell-Larcker criterion.

\begin{tabular}{cccccccc}
\hline & BEN & CERT & COL & IU & PEU & PU & SEC \\
\hline BEN & 0.710 & & & & & & \\
CERT & 0.500 & 0.719 & & & & & \\
COL & 0.410 & 0.673 & 0.796 & & & & \\
IU & 0.423 & 0.550 & 0.435 & 0.854 & & & \\
PEU & 0.441 & 0.640 & 0.729 & 0.553 & 0.777 & & \\
PU & 0.488 & 0.612 & 0.619 & 0.691 & 0.560 & 0.711 & \\
SEC & -0.307 & -0.159 & -0.157 & -0.145 & -0.174 & -0.273 & 0.761 \\
\hline
\end{tabular}

As shown in Table 7, all of the variables displayed acceptable discriminant validity using the HTMT test as well as bearing values below thresholds of $0.90[111,112]$.

Table 7. Discriminant validity: Heterotrait-Monotrait ratio (HTMT).

\begin{tabular}{cccccccc}
\hline & BEN & CERT & COL & IU & PEU & PU & SEC \\
\hline BEN & & & & & & & \\
CERT & 0.616 & & & & & & \\
COL & 0.496 & 0.868 & & & & & \\
IU & 0.535 & 0.666 & 0.534 & & & & \\
PEU & 0.483 & 0.787 & 0.891 & 0.647 & & & \\
PU & 0.638 & 0.793 & 0.796 & 0.879 & 0.698 & & \\
SEC & 0.471 & 0.203 & 0.223 & 0.200 & 0.230 & 0.365 & \\
\hline
\end{tabular}

\subsection{Structural Model}

To assess the structural model, a three-stage approach was carried out by the authors [111-113]; firstly, the $\mathrm{R}^{2}$ value was obtained for each latent variable. Secondly, a redundancy check of $\mathrm{Q}^{2}$ was calculated by using a blindfolding function to ascertain the quality of predictive relevance. Thirdly, the bootstrap function was used to assess whether the path coefficients of the structural model are significant or not and if their effect size is sufficiently big enough. A one-tailed test was used because of the predetermined direction of relationship between all hypothesized variables of the theoretical framework. A 5000 bootstrap sample was used for this study constituting the same number of observations as that of the original sample in order to generate the standard errors and $t$-values [101]. In addition, the interaction effect was checked through $\mathrm{f}^{2}$ values representing effect size. The coefficient 
of the determinant "R-square" value represents how much variance in a target variable is explained by the effect size of the independent variables linked to it [113]. Chin (1998) recommended benchmark values for R-square as 0.67 (substantial), 0.33 (moderately strong) and 0.19 (weak).

(Security $\beta=-0.121$; Collaboration $\beta=0.296$; Certainty $\beta=0.256$ ) along with PEU $(\beta=0.085)$ explained $50.2 \%$ variance in PU. Whereas $58.2 \%$ of the variance in PEU was explained by the four EREB dimensions (Benefits $\beta=0.102$; Security $\beta=-0.023$; Collaboration $\beta=0.529$; Certainty $\beta=0.230$ ). Moreover, PEU ( $\beta=0.243)$ and PU ( $\beta=0.555)$ explained $51.8 \%$ of the variance in IU.

Benefits had a significant positive effect on PEU $(t=2.295, p=0.022)$ as well as PU $(t=3.383$, $p=0.001$ ). Security concerns of employees showed an insignificant (although negative) relationship with PEU $(\mathrm{t}=1.577, p=0.115)$; however, it did prove to have a significant negative relationship with $\mathrm{PU}(\mathrm{t}=3.050, p=0.002)$ as initially hypothesized. Certainty had a significant positive relationship with PEU $(\mathrm{t}=4.046, p<0.001)$ and PU $(\mathrm{t}=3.669, p<0.001)$. Collaboration also had a significant positive effect on both PEU $(t=10,914, p<0.001)$ as well as PU $(t=5.677, p<0.001)$. Moreover, PEU $(t=5.479$, $p<0.001$ and $\mathrm{PU}(\mathrm{t}=13.182, p<0.001)$ both had a significant positive effect on intention to use.

The $\mathrm{t}$-value test for level of significance has been calculated by using two-tailed estimation (Hair et al. 2013). Table 6 shows the $t$-values and p-values indicating that Security did not prove to have a significantly negative relationship with perceived ease of use $(t=0.596, p=0.551)$ and PEU did not prove to have any significant effect on PU $(t=1.577, p=0.115)$. All other direct relationships proved to be significant with $t$-values well above a threshold of 1.96 and p-values of less than 0.05 .

Keeping this in mind, and based on the $t$-value rule of thumb for interpretation of a two-tailed test i.e., $\mathrm{t}=1.96$, all the hypotheses were supported with two exceptions, namely $\mathrm{H} 1$ and H5a.

Figure 2 displays the path coefficient values and $t$-values (in parentheses) along with the R-square variance in perceived ease of use, perceived usefulness and intention to use, as explained by other independent variables.

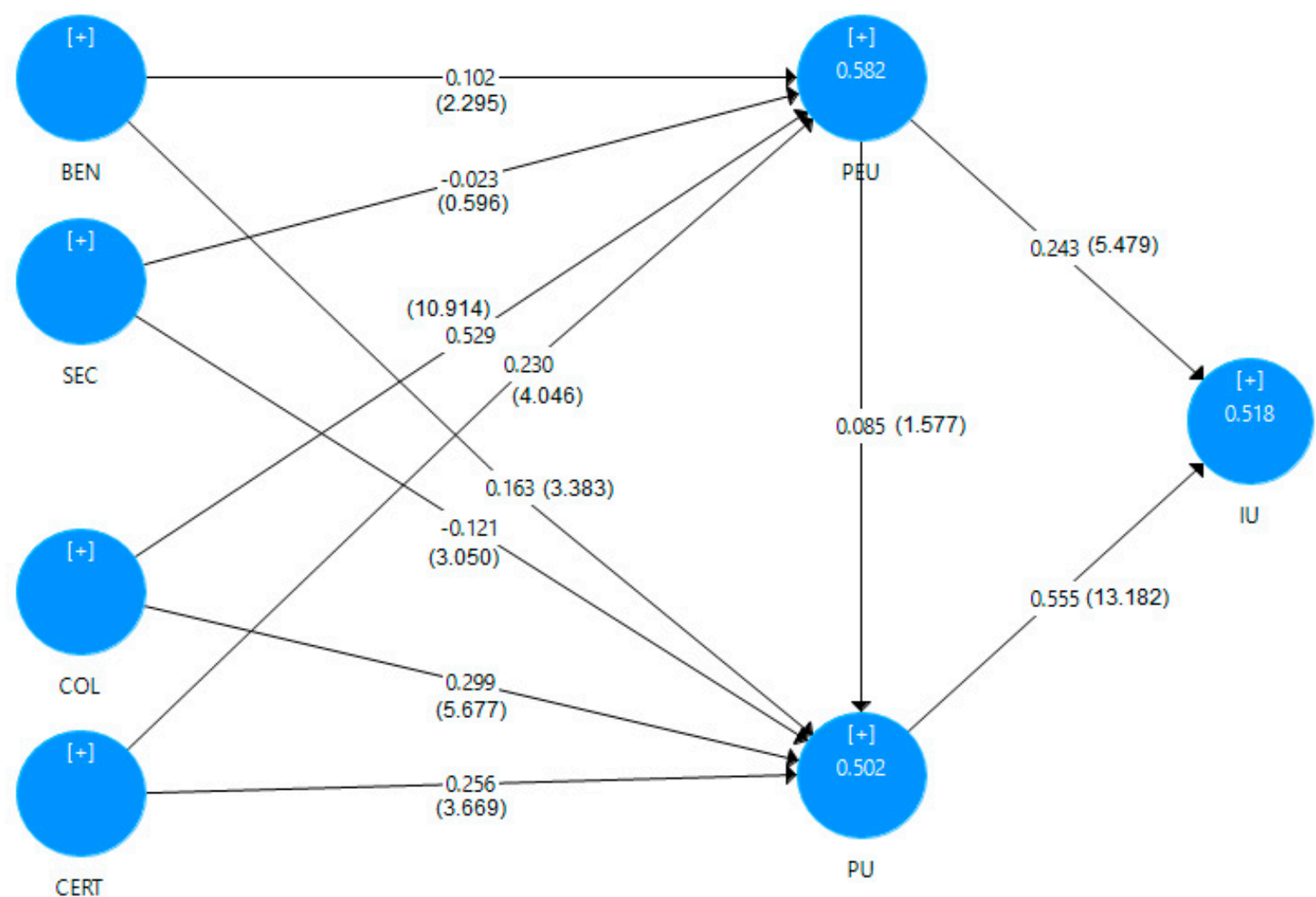

Figure 2. Results of the model. 


\subsection{Model Strength and Quality}

As recommended by [105], $\mathrm{f}^{2}$ values of $0.02,0.15$ and 0.35 indicate that the interaction term is low, medium, or large on the criterion variable respectively. $\mathrm{A}^{2}$ value of greater than zero implies that the model has good predictive relevance [116].

Table 8 shows the results of the model obtained through PLS Algorithm function under smartPLS software calculate the table. Table 9 displays the values for $\mathrm{f}^{2}$ were obtained from the measurement model results and the $Q^{2}$ values obtained through the blindfolding function. It is evident from the figures that the relationship paths from BEN to PEU $\left(f^{2}=0.017\right)$, SEC to PEU $\left(f^{2}=0.001\right)$ and PEU to PU $\left(f^{2}=0.006\right)$ bear a low interaction because $\mathrm{f}^{2}$ values are below the minimum 0.02 threshold. The strongest interaction term was between PU and IU with a substantially large $\mathrm{f}^{2}$ value of 0.439 . Similarly, the COL to PEU path was also very strong with an $\mathrm{f}^{2}$ value of 0.362 .

Table 8. Results of the model-mean, STDEV, T-values, $P$-values.

\begin{tabular}{ccccccc}
\hline Hypotheses & $\begin{array}{c}\text { Original } \\
\text { Sample (O) }\end{array}$ & $\begin{array}{c}\text { Sample } \\
\text { Mean (M) }\end{array}$ & $\begin{array}{c}\text { Std Dev. } \\
\text { (STDEV) }\end{array}$ & $\begin{array}{c}\text { T-Value } \\
(\mid \mathbf{O} / \text { STDEV|) }\end{array}$ & $\begin{array}{c}\boldsymbol{P} \\
\text { Values }\end{array}$ & Results \\
\hline H4a = BEN->PEU & 0.089 & 0.093 & 0.039 & 2.295 & 0.023 & Supported \\
H4b = BEN->PU & 0.159 & 0.162 & 0.047 & 3.383 & 0.001 & Supported \\
H7a $=$ CERT->PEU & 0.231 & 0.233 & 0.057 & 4.046 & $<0.001$ & Supported \\
H7b = CERT->PU & 0.252 & 0.249 & 0.069 & 3.669 & $<0.001$ & Supported \\
H6a = COL->PEU & 0.536 & 0.532 & 0.049 & 10.914 & $<0.001$ & Supported \\
H6b = COL->PU & 0.282 & 0.283 & 0.050 & 5.677 & $<0.001$ & Supported \\
H2 = PEU->IU & 0.241 & 0.240 & 0.044 & 5.479 & $<0.001$ & Supported \\
H1 = PEU->PU & 0.112 & 0.113 & 0.071 & 1.577 & 0.108 & Not Supported \\
H3 = PU->IU & 0.559 & 0.560 & 0.042 & 13.182 & $<0.001$ & Supported \\
H5a = SEC->PEU & -0.023 & -0.025 & 0.039 & 0.596 & 0.547 & Not Supported \\
H5a $=$ SEC->PU & -0.119 & -0.120 & 0.039 & 3.050 & 0.002 & Supported \\
\hline
\end{tabular}

Table 9. Model strength and quality.

\begin{tabular}{|c|c|c|c|c|c|c|c|c|}
\hline & \multicolumn{4}{|c|}{ f Square } & \multirow[t]{2}{*}{ R-Square } & \multicolumn{3}{|c|}{ Q Square } \\
\hline & IU & PEU & PU & SEC & & SSO & SSE & $\mathrm{Q}^{2}(=1-\mathrm{SSE} / \mathrm{SSO})$ \\
\hline BEN & & 0.017 & 0.036 & & & 1655.000 & 1193.519 & 0.279 \\
\hline CERT & & 0.062 & 0.060 & & & 1655.000 & 1165.292 & 0.296 \\
\hline COL & & 0.362 & 0.071 & & & 1324.000 & 817.128 & 0.383 \\
\hline SEC & & 0.001 & 0.027 & & & 1324.000 & 896.662 & 0.323 \\
\hline PEU & 0.084 & & 0.006 & & 0.577 & 1655.000 & 994.740 & 0.399 \\
\hline PU & 0.439 & & & & 0.494 & 1655.000 & 1198.213 & 0.276 \\
\hline IU & & & & & 0.515 & 993.000 & 561.904 & 0.434 \\
\hline
\end{tabular}

The R-square values for IU, PU and PEU were $0.515,0.494$ and 0.577 respectively, displaying a moderately strong explanation of variance by the independent variables. The Q2 values for all the relationships were above zero, thus meeting the minimal criterion as required by the existing literature.

\subsection{Higher Order Construct of EREB}

In order to check whether the relation between EREB and intention to use is partially or fully mediated by PEU and PU, higher order construct of EREB was created by using a two-step approach recommended by Becker, Klein and Wetzels [117] in cases where the different constructs have different numbers of items in order to assure relatively lesser bias in results. To obtain this, we convert the latent variables into items for the higher order construct, i.e., in this study, Benefits, Security, Collaboration and Certainty are four variables with varying numbers of items, we shall use them as items for a higher order construct EREB. In order to achieve this, we run the four lower order variables in the model using the PLS Algorithm in SmartPLS. From the measurement model results output, all the 'Latent variable scores' were copied into the original data file and saved as new items. Then this newly changed data file is used as the source data file to create EREB as a latent variable using the latent 
variables Benefits, Security, Collaboration and Certainty as items. As Becker, Klein and Wetzels [117] recommended, the measurement model is run again and the reliability and validity of the higher order model is also checked, just as it was done above for the lower-order constructs. Table 10 displays the relevant values for measurement model results.

Table 10. Reliability and validity of higher order model.

\begin{tabular}{ccccc}
\hline & Cronbach's Alpha & Rho A & C.R. & AVE \\
\hline EREB & 0.714 & 0.767 & 0.826 & 0.552 \\
IU & 0.787 & 0.825 & 0.875 & 0.703 \\
PEU & 0.833 & 0.847 & 0.880 & 0.597 \\
PU & 0.731 & 0.742 & 0.824 & 0.586 \\
\hline
\end{tabular}

The internal consistency reliability of the higher order construct EREB was established using a composite reliability value of 0.826 . The rho A value was 0.767 while Cronbach's Alpha was 0.714 . Moreover, the convergent validity was established through the AVE value, which was 0.552.

A 5000-sample bootstrap was run to check the model with higher order construct. Results displayed in Table 11 and Figure 3 below indicate that that EREB explained 54.3\% variance in PU and $46.9 \%$ variance in PEU. Moreover, PEU, PU and EREB together explained $48.4 \%$ variance in IU. All the relationship paths had f-square values of above 0.15 , which signifies a moderately strong relationship [105], except for PEU to PU (f-square $=0.014$ ) which means the relationship is not as meaningful as it was below the minimum 0.02 benchmark. This was consistent with the lower order model run previously with four latent variables of EREB.

Table 11. Strength and quality of the higher-order model.

\begin{tabular}{ccccc}
\hline & \multicolumn{3}{c}{ f-Square } & R Square \\
\hline EREB & IU & PEU & PU & \\
IU & & 0.387 & 0.295 & \\
PEU & 0.16 & & 0.014 & 0.543 \\
PU & 0.41 & & & 0.469 \\
\hline
\end{tabular}

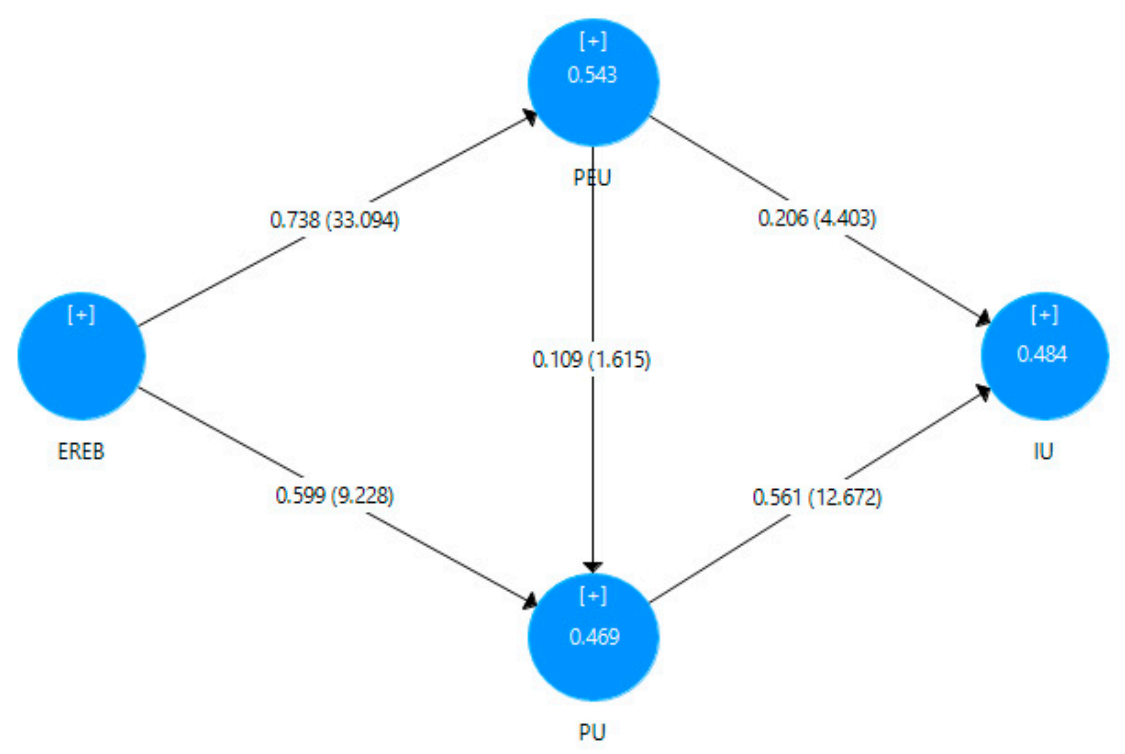

Figure 3. Results of the higher model. 


\subsection{Mediation Results}

Mediation was assessed using the variance accounted for (VAF) method recommended by Preacher and Hayes [118] and also suggested by Hair, Hult, Ringle and Sarstedt [106]. PU and PEU were run together in the model instead of separately. They were added one-by-one to the model, which is similar to the method adopted in a recent study by Martinez-Martinez, Herrera Madueno, Larran Jorge and Lechuga Sancho [119]. It was found that PEU and PU both fully mediate the relationship between EREB and IU, as the variance accounted for value exceeds the $80 \%$ benchmark devised by Preacher and Hayes [118]. The variance accounted for is calculated by dividing the point estimate (multiplication of path values) by the total effect of the independent variable (IV) on the dependent variable (D.V).

As per the method devised by Preacher and Hayes [118], there is no mediation if the VAF value is less than $20 \%$; full mediation if the VAF value is $80 \%$ or above and partial mediation when the values of VAF lies between $20 \%$ and $80 \%$. The individual paths for PEU and PU were observed to partially mediate the relationship between EREB and IU. PEU's VAF value was $29.45 \%$, which suggests partial mediation. PU's VAF value was $60.80 \%$, which also indicates partial mediation. The sequential path through both PEU and PU showed no mediation as the VAF value was 9.73\%.

$$
\begin{aligned}
& \text { Variance Accounted for }=\text { Point Estimate/Total Effect of IV on DV } \\
& \text { VAF }=\mathrm{a} 1 \mathrm{~b} 1+\mathrm{a} 2 \mathrm{~b} 2+\mathrm{a} 1 \mathrm{c} 1 \mathrm{~b} 2 /(\text { Total Effect })=0.5329 / 0.533=99.99 \%
\end{aligned}
$$

Table 12 shows the values and calculations involved. Individual mediations via PEU and PU were separately calculated as below:

$$
\begin{gathered}
\text { EREB- }>\text { PEU- }>\mathrm{IU}=(\mathrm{a} 1 \mathrm{~b} 1) /(\text { Total Effect })=0.1570 / 0.533=29.45 \% \\
\text { EREB->PU->IU }=(\mathrm{a} 2 \mathrm{~b} 2) /(\text { Total Effect })=0.3241 / 0.533=60.80 \% \\
\text { EREB-PEU-PU-IU }=(\mathrm{a} 1 \mathrm{c} 1 \mathrm{~b} 2) /(\text { Total Effect })=0.0519 / 0.533=9.73 \%
\end{gathered}
$$

\begin{tabular}{|c|c|c|c|c|c|c|c|}
\hline \multicolumn{2}{|c|}{ Total Effect of EREB } & \multicolumn{2}{|c|}{ Direct Effect of EREB } & \multicolumn{4}{|c|}{ Indirect Effects of EREB } \\
\hline \multirow[t]{2}{*}{ Coefficient } & \multirow[t]{2}{*}{$\mathrm{t}$-value } & \multirow[t]{2}{*}{ Coefficient } & \multirow[t]{2}{*}{$\mathrm{t}$-value } & & \multirow[t]{2}{*}{$\begin{array}{c}\text { Point } \\
\text { estimate }\end{array}$} & \multicolumn{2}{|c|}{$\begin{array}{c}\text { Percentile bootstrap } \\
95 \% \text { confidence } \\
\text { interval }\end{array}$} \\
\hline & & & & & & Lower & Upper \\
\hline \multirow[t]{4}{*}{0.533} & $17.956 *$ & 0.097 & $1.326^{*}$ & $a 1 b 1+a 2 b 2+a 1 c 1 b 2$ & 0.5329 & & \\
\hline & $($ EREB- $>$ PE & EU-> IU) = a1b1 & & $=0.737 \times 0.213$ & 0.1570 & 0.096 & 0.212 \\
\hline & $($ EREB- $>\mathrm{I}$ & $\mathrm{U}->\mathrm{IU})=\mathrm{a} 2 \mathrm{~b} 2$ & & $=0.585 \times 0.554$ & 0.3241 & 0.247 & 0.419 \\
\hline & $->\mathrm{PEU})(\mathrm{PI}$ & PU) $(P U->I U)=a$ & $1 \mathrm{~b} 2$ & $=0.737 \times 0.127 \times 0.554$ & 0.0519 & 0.004 & 0.096 \\
\hline
\end{tabular}

Table 12. PU and PEU: mediation effect results.

${ }^{*} p<0.05$ [based on a t distribution $(4999)$, one-tailed test: $\mathrm{t}(0.05 ; 4999)=1.645$ ]. The bold above shows the total indirect effect formula and its point estimate value.

\section{Discussion}

Firstly, the results show that employees who display e-business readiness tend to focus on the benefits of the new technology or software and are more inclined to utilize it in job tasks for improved performance, efficiency and gaining greater control in job tasks leading to greater job satisfaction [18]. This helps expedite the DSS implementation process. Expected benefits from the use of technology are that it motivates employees and creates a perception of ease of use and usefulness, as found in our study. As Lee, Park and Bakers [93] argue, in the present day competitive job market, employees must enhance skills and abilities to be of value to their employer, which is why the employees place more value on any learning opportunity that could enhance their competency. New technology introduced in the workplace is one such opportunity that brings benefits for employees and leads to satisfaction from learning achievement outcomes and job performance; as a result, bringing a perception of usefulness leading to intention to use of DSS. 
Secondly, this study shows a positive relationship of Certainty with PEU and PU, portraying that employee trust in management creates better readiness. Previous research conducted from an employee perspective [9] also showed similar results where trust showed a significant effect on e-business value creation. Whenever an infrastructure for training and support is available to employees, it builds trust in management and creates certainty in their perceptions towards DSS adoption and use; employees receive it well with the certainty that the organization and management have the capability [18] to carry out the successful implementation of DSS. Employees who display higher certainty about management's capabilities and trust that e-business readiness will be helpful in supporting change initiatives, including technology changes such as DSS, simultaneously creating intention to use DSS.

Thirdly, based on the results, collaborative efforts create an environment of learning and knowledge sharing, which promotes the perception of ease of use and usefulness through shared experiences by employees. It implies that participative behavior promotes perceptions of ease and usefulness. Lai, Kan and Ulhas [9] also found that participation by employees was significant in creating e-business readiness. Management should thus motivate employees through a systematic method [120] both emotionally as well as technically. Encouraging employees to collaborate and participate could be done through training specific to e-business processes involving the use of DSS. This in turn can result in greater commitment towards e-business readiness and technology use while aligning business goals with employee job satisfaction.

Fourthly, contrary to the other three dimensions of e-business readiness, employee security concerns play a volatile role if not addressed properly by management. Results show that concerns were negatively related to perceived usefulness of any given technology. This brings resistance to change by employees. However, this can be countered by maintaining a healthy environment in the workplace by ensuring an individual-technology fit and task-technology fit through training. This is in line with previous studies stating that employee professional-development opportunities are important for employees to maintain their job security [93]. By knowing the capabilities of the workforce, identifying the technological knowledge gap and eliminating these gaps through training, monitoring and feedback, employee security concerns can be mitigated.

Results also showed job security has no significant impact on PEU for DSS, mainly because of the underlying fact that in case of job security concerns, an employee would not be bothered as to whether a technology is easy to use or not as they are more concerned with retaining the job role; it is not an immediate concern for an employee since it could cause them loss of influence, change in their job role or even unemployment. Employees' perceptions about job insecurity are closely associated with their behavior towards technology use [76]. It causes stress for employees and can cause anxiety and other negative outcomes [79]. Once an employee sees the technology as a threat or feels insecure, the focus shifts from the technology to his or her own survival and fear of unemployment in the long run [78]. It can, therefore, be argued that when an employee is concerned that new technology may not be useful for them, the focus shifts to job security. Stress and anxiety stemming from a new technology in the workplace make an employee indifferent to the fact of whether it is easy to use or not. Similarly, the same line of argument holds true for the insignificant path from PEU to PU. If a technology is easy to use, employees will continue to use it; they will not stress about whether it is useful or not. Job insecurity results in feedback seeking behavior by employees [82], usefulness of a technology will not depend on whether it is easy to use or not and an employee's technology usage behavior remains stable if the new technology does not threaten their job security [76].

\section{Theoretical and Practical Implications}

The present study contributes in three ways. Firstly, it combines and analyzes the relationship between two models i.e., EREB and TAM, which has not been done before. Secondly, this study examines the level of employees' e-business readiness and its relationship with technology acceptance. Moreover, it studies the resistance to DSS because of being inhibited by employee security concerns. 
Thirdly, the results above show that three constituent factors of EREB have positive effects on the perceived usefulness and perceived ease of use in the use of decision support systems.

Information systems, unlike the personal use technologies, are primarily utilized in work-settings for performance of job tasks. By assessing the IS adoption and its use, this study makes a contribution to technology acceptance model literature by empirically showing that adoption and continued usage of group-based technologies in the e-business workplace is dependent on employee readiness. This is determined by individual employee's perceptions about the four dimensions i.e., Benefits, Collaboration, Certainty and Security, stemming from existing organizational culture regarding employee preparedness.

This study not only affirms the past findings for the core constructs of the TAM model i.e., PEU and PU; it also further introduces the four constructs of EREB as predictors of PEU and PU. It studied PU and PEU strictly from an employee's point of view as a user of technology. Moreover, PEU and PU fully mediate the relationship between higher order EREB constructs and intention to use DSS. The results affirm that perceived benefits of a technology shall create a positive effect on PEU and PU. Expected benefits from the use of DSS create positive intention to use DSS through perceived usefulness. Certainty and employees' perception about the management's ability to successfully implement DSS shall lead to positive perceptions about PEU and PU and creates positive intention to use DSS. Collaboration and participation by employees accelerates the adoption as it creates a harmonious perception among employees. An environment of collaboration and sharing in the workplace shall lead to intention to use DSS and is mediated by perceived usefulness and ease of use.

Although technology has been discussed in literature with ample evidence provided by proven studies, the evaluated phenomenon on most occasions tends to be the overall ability of the organizational adaptive capability, the customer's readiness for a particular technology, or the supplier's integration with the system between buyer and supplier from a supply chain point of view. However, there is lack of substantive research on readiness of employees for e-business in conjunction with technology acceptance for a decision support system.

More specifically, technology acceptance research is comparatively much less focused on the employee as the unit of analysis. This issue lacks academic research from an employees' perspective when it comes to technology-intensive e-business firms as well. This research studies the construct "employee readiness for e-business" (EREB) proposed by [18] and developed as a multiple-item measurement scale in order to assess the level of employee readiness for e-business tasks while purely focusing on the employee's perspective as the user of technology. Thus, this study adds to the knowledgebase on the subject of technology usage behavior in e-business firms from a change management viewpoint and the employees' perceptions about new technology in the workplace. It will be useful for researchers and practitioners interested in designing, implementing, and managing e-business technologies.

New technology or software inherently brings about change [35]. Whenever an information system is introduced into the organizational setting, there is bound to be a change in the previous process and the procedures of running routine business matters and job tasks. Thus, business process re-engineering comes into play to enable a smooth transition into new procedures and processes. Readiness for change is dependent on a multiple number of factors. From the start, managers and practitioners need to create awareness and collaboration through training sessions, closed group discussions, planning and building trust with employees before a new information system is introduced.

Therefore, there is need to build an optimistic environment and minimize resistance towards technological changes in the workplace. This brings us to the widely researched task-technology-fit (TTF) concept [121] that mainly focuses on "the appropriateness of the technology to the task" and employees' perceptions towards the degree to which functions of a technology assist them in performing their work.

More specifically, in e-business environments, in particular the benefits of using Decision Support Systems as perceived by employees, and information systems in general, is likely to increase when a 
task-technology and an individual-technology fit is ensured primarily because it builds a rapport of usefulness as it sits well with employee values and ease of use because they feel it is made specifically for their tasks [19].

It is argued that DSS implementation can be divided into two dimensions [122]. The first is termed 'technology performance' wherein DSS usage is aimed at fetching better outcomes and recommendations from the use of technology (technology performance). The second is termed as 'task performance', which entails utilizing outputs of a given DSS. Past empirical research shows that when technology performance enhances, it leads to better task performance $[57,122,123]$.

Table 13 presents a matrix for a combination of anticipated perceptions that each dimension of EREB creates for employees and what steps management personnel should introduce beforehand to lead to a successful transition to a new technology or to ensure the continued use of existing technology.

Table 13. Matrix for proposed managerial actions and underlying employee perceptions.

\begin{tabular}{|c|c|c|c|}
\hline \multirow{2}{*}{$\begin{array}{c}\text { EREB } \\
\text { Dimensions }\end{array}$} & \multicolumn{2}{|c|}{ Employee Perceptions } & \multirow{2}{*}{$\begin{array}{l}\text { Proposed Pro-Active } \\
\text { Managerial Steps }\end{array}$} \\
\hline & Extrinsic Motivators & Intrinsic Motivators & \\
\hline Benefits & $\begin{array}{l}\text { Be the first movers/adopters for } \\
\text { financial gain }\end{array}$ & $\begin{array}{l}\text { Getting to experience the new } \\
\text { technology before others (for } \\
\text { employees with personal } \\
\text { innovativeness and high } \\
\text { self-efficacy) }\end{array}$ & $\begin{array}{l}\text { Monetary rewards to } \\
\text { motivate early adoption } \\
\text { of technology }\end{array}$ \\
\hline Security & $\begin{array}{l}\text { Possible financial loss due to fear } \\
\text { of losing their job, loss of power or } \\
\text { change of role in the workplace }\end{array}$ & $\begin{array}{l}\text { Social norms; face-saving; loss of } \\
\text { reputation amongst family and } \\
\text { friends }\end{array}$ & $\begin{array}{l}\text { Create } \\
\text { individual-technology-fit; } \\
\text { awareness campaigns; } \\
\text { training; discussion } \\
\text { sessions }\end{array}$ \\
\hline Collaboration & $\begin{array}{l}\text { Be a visible contributor for } \\
\text { prospective promotion } \\
\text { opportunities to managerial roles }\end{array}$ & $\begin{array}{l}\text { Social acceptance/subjective } \\
\text { norms; winning friends in the } \\
\text { workplace }\end{array}$ & $\begin{array}{l}\text { Feedback to and from } \\
\text { employees to establish a } \\
\text { culture of cooperation } \\
\text { and knowledge-sharing }\end{array}$ \\
\hline Certainty & $\begin{array}{l}\text { Task-technology fit through better } \\
\text { focus on learning and attaining } \\
\text { individual-technology-fit for } \\
\text { mandatory job tasks; }\end{array}$ & $\begin{array}{l}\text { Trust in management's ability to } \\
\text { implement the new } \\
\text { technology/systems; trust in } \\
\text { cooperation }\end{array}$ & $\begin{array}{l}\text { Test runs; } \\
\text { implementation in } \\
\text { batches of small teams }\end{array}$ \\
\hline
\end{tabular}

Source: Authors own construction.

Integration of resources and systemic storage, transmission and analysis of business information is an imperative objective at present day organizations as they try to integrate the operations between employees, departments, vendors, and suppliers to optimize processes and add value to business. Thus, there is an increasing focus on implementation of electronic business (e-business) activities. This issue further fuels debate on determining employee readiness towards this new type of organization [18]. However, the firms who are considered e-businesses have to upgrade existing technology or introduce new technology with the passage of time.

A task-technology fit needs attention at the beginning of the very process of buying/building a new information system. When the task is the center of attention when building the IS, it brings harmony in job task performance without causing employees anxiety. A well-thought out DSS reduces the gap between an individual's ability to attain a certain level of expertise and the need to achieve certain level of task performance. The individual-technology fit is to be handled on a continuous level [123]. This fit, if not established by the management for the employees, leaves a gap in the employees' preparedness and readiness due to probable security concerns related to their job, arising from changes brought by the new technology i.e., information systems or decision support systems.

It is not necessarily the insecurity of losing the job altogether, but in fact, the fear of losing influence amongst peers, losing their power at workplace or simply a change in job role. Before selecting, building or introducing new information, if employee feedback is obtained to make them feel included 
in the process of technology adoption, it will serve as a mode of building trust, creating readiness for change, and inherently ensuring a task-technology and an individual-technology fit.

Regular and routine inculcation of training, idea-generation and feedback sessions tend to build trust and certainty among the employees and enhances their perception of the management's ability to successfully implement the new technological changes, leading to improved technology adoption behavior and continued intention towards technology use. Moreover, collectivism built by this trust also helps employees to be more open and more collaborative as a result of the environment of ease and satisfaction. It is always a collaborative effort that results in the successful implementation of technology in any organization, the employee being the basic unit of change.

\section{Conclusions, Limitations and Future Research}

The management has a key role to play in creating positive perceptions about the EREB dimensions i.e., Benefits, Certainty, Security and Collaboration. This can be achieved through the inculcation of regular trainings, feedback, offering rewards and ensuring a secure job environment. Moreover, employee security concerns are inversely related to ease of use and usefulness of decision support systems. The two hypotheses that were not supported i.e., Security->PEU and PEU->PU, both indicate that once an employee feels anxiety about losing power and authority in their job role or even fears unemployment due to the introduction of a new technology; the primary focus shifts from perceptions about ease of use or usefulness to anxiety, fear and survival.

It can be argued that optimizing output is inherently a key part of human nature. The behavioural outcomes with respect to perceptions about ease of use and usefulness are similar for both employees and customers because they are devoid of any influence from the environment in which a technology may be introduced i.e., whether it is in workplace settings for employees or in marketplace settings for customers. The variables PEU and PU are being measured for employees in this study with the modified version of the same scale and instrument used for customers in past studies. The results are also similar because the TAM model does not differentiate between customers and employees as "users" of technology.

This study is unique because it introduces EREB as predictor of PEU and PU in technology adoption literature. Moreover, PEU and PU fully mediate the relationship between higher order EREB construct and intention to use DSS. The results are unique and significant because they provide four new dimensions of employee behavior that are vital in building perceptions about ease and usefulness. Firstly, if employees perceive that there will be higher benefits from use of a new technology, they will be more willing to adopt it because of higher PEU and PU. Secondly, another unique and significant finding of this study is the relationship of certainty with PEU and PU. If the employee's perception about management capability to successfully implement changes at work (certainty) is high, then it shall lead to a higher level of PEU and PU leading to intention to use DSS. Collaboration and participation by employees accelerates the adoption as it creates a harmonious perception among employees. An environment of collaboration and sharing at workplace shall lead to intention to use DSS and is mediated by perceived usefulness and ease of use.

The two hypotheses that were not supported i.e., Security->PEU and PEU->PU, both indicate that once an employee feels anxiety about losing power and authority of his job role or even fears unemployment due to introduction of a new technology; the primary focus shifts from perceptions about ease of use or usefulness onto anxiety, fear and survival.

This study adds new theoretical perspective of employee behavior in technology adoption instead of consumer behavior. Employee is studied as a unit of analysis as against past literature which focuses on consumer as a unit of analysis for technology adoption for e-business firms. It is a theoretical contribution of this research because it uses TAM model to study user behavior from employee's perspective. Past literature on technology adoption shows studies from consumer behavior, student behavior or teacher's behavior. However, it lacks studies on behavior of employees of e-business firms. 
The methodological contribution of this study is that it was known that the sample (respondents) is experienced and expert in technology use and works in a technology-intensive organization. This is different from past studies where mixed respondents have been used as sample. Either past studies do not bifurcate between experienced or non-experienced users or it is not known in majority of studies whether the sample is made of respondents who are adept in use of technology and whether they work in a technology-intensive environment or not.

Mandatory use of technology vs. choice of use; it is mandatory for individual users who do not have a choice in adoption of technology; instead they have to comply with company-wide regulations. So, this aspect makes it a certain factor that it will affect the job security of employees.

This study not only identifies four factors that shape employee behavior towards technology adoption in e-business firms, but also suggests a specific managerial course of action for each of these four factors. Managerial actions proposed above aim at creating a positive employee behavior by paying attention to the extrinsic as well as intrinsic motivational factors behind these four specific dimensions that constitute EREB.

This study also has its limitations. Firstly, this study followed a cross-sectional study design; although it is a common practice in similar research, researchers still consider this a limitation. Secondly, even though the sample size in this study was appropriate from the analysis and theoretical point of view, the authors consider the sampling method to be a limitation. Secondly, the sample was taken from the UK, a larger sample size with a more diverse geographical range of respondents from another country or multiple countries shall further enhance statistical power to achieve more generalizable results. Thirdly, the sample was also restricted to technology-intensive travel and tourism companies; it does not cater for the businesses that are not categorized as e-businesses and are potentially looking forward to becoming e-businesses. Fourthly, this paper studied the impact on employee-perceived benefits of e-business-Certainty, Security and Collaboration-as antecedents of TAM. However, these are not the sole determinants of employee readiness in a firm's overall technology readiness; the technology readiness index is one such example of another measure. Thus, technology acceptance could also be driven by certain other employee-specific or firm-specific antecedents which were not part of our study. Last but not least, this study's sample is limited to SMEs, it does not cover micro-sized organizations in the UK.

Keeping the aforementioned limitations in mind, we suggest using a wider variety of firms with a broader number of fields such as SEOs, social media marketing as well as other digital advertising and service-oriented firms for possible future research. It is suggested that micro-sized organizations in the UK may also be included in future research. We also suggest including factors other than institutional support from a firm-specific viewpoint; employees' level of 'Readiness for Change' and 'Perceived Personal Competence' in technology as antecedents of EREB or mediators/moderators between EREB and TAM. Furthermore, considering that there has been some research carried out in previous studies on relationship between the TAM and TTF models, future research may be carried out to check a moderating effect of TTF on the relationship between the dimensions of EREB and TAM.

Author Contributions: Conceptualization, F.A. and Y.J.Q.; methodology, F.A. and L.M.; software, Y.J.Q.; validation, F.A., Y.J.Q. and L.M.; formal analysis, F.A.; investigation, F.A.; resources, L.M.; data curation, F.A. and Y.J.Q.; writing-original draft preparation, F.A.; writing—review and editing, F.A., L.M.; visualization, F.A.; supervision, Y.J.Q.; project administration, L.M.; funding acquisition, L.M.

Funding: This research was partially funded by SPANISH NATIONAL RESEARCH PROJECT, grant number TIN2015-66524-P and ERDF.

Acknowledgments: We would like to thank our colleagues Ali Raza, Naveed Ahmad Faraz and Muhammad Khalid Iqbal for their guidance on methodology and data analysis of this paper and advice for the subsequent revisions.

Conflicts of Interest: The authors declare no conflict of interest. 


\section{References}

1. Alaba, F.A.; Othman, M.; Hashem, I.A.T.; Alotaibi, F. Internet of Things security: A survey. J. Netw. Comput. Appl. 2017, 88, 10-28. [CrossRef]

2. Gu, F.; Ma, B.Q.; Guo, J.F.; Summers, P.A.; Hall, P. Internet of things and Big Data as potential solutions to the problems in waste electrical and electronic equipment management: An exploratory study. Waste Manag. 2017, 68, 434-448. [CrossRef]

3. Ericsson. Ericsson-Mobility-Report; Ericsson: Stockholm, Sweden, 2016.

4. Bosch, J.; Olsson, H.H. Toward Evidence-Based Organizations: Lessons from Embedded Systems, Online Games, and the Internet of Things. IEEE Softw. 2017, 34, 60-66. [CrossRef]

5. Giannino, F.; Esposito, S.; Diano, M.; Cuomo, S.; Toraldo, G. A predictive Decision Support System (DSS) for a microalgae production plant based on Internet of Things paradigm. Concurr. Comput. Pract. Exp. 2018, 30, e4476. [CrossRef]

6. Schumpeter, J. The Theory of Economic Development; Transaction Publishers: New Brunswick, NJ, USA, 1934.

7. Euripidis, L.; Fotini, M. ERP and E-Business Systems Development, Innovation and Business Performance-An Empirical Investigation. In Proceedings of the 2012 45th Hawaii International Conference on System Sciences, Maui, HI, USA, 4-7 January 2012; pp. 4682-4691. [CrossRef]

8. Eagleman, A.N. Acceptance, motivations, and usage of social media as a marketing communications tool amongst employees of sport national governing bodies. Sport Manag. Rev. 2013, 16, 488-497. [CrossRef]

9. Lai, J.-Y.; Kan, C.-W.; Ulhas, K.R. Impacts of employee participation and trust on e-business readiness, benefits, and satisfaction. Inf. Syst. e-Bus. Manag. 2012, 11, 265-285. [CrossRef]

10. Masum, A.K.; Beh, L.S.; Azad, A.K.; Hoque, K. Intelligent Human Resource Information System (i-HRIS): A Holistic Decision Support Framework for HR Excellence. Int. Arab J. Inf. Technol. 2018, 15, 121-130.

11. Yang, Z.; Sun, J.; Zhang, Y.; Wang, Y.; Cao, L. Employees' collaborative use of green information systems for corporate sustainability: Motivation, effort and performance. Inf. Technol. Dev. 2017, 23, 486-506. [CrossRef]

12. Leana, C.; Rousseau, D. Relational Wealth: The Advantages of Stability in a Changing Economy; Oxford University Press: Oxford, UK, 2000.

13. Bigi, M.; Greenan, N.; Hamon-Cholet, S.; Lanfranchi, J. The Human Sustainability of ICT and Management Changes: Evidence for the French Public and Private Sectors. Sustainability 2018, 10, 3570. [CrossRef]

14. Moja, L.; Passardi, A.; Capobussi, M.; Banzi, R.; Ruggiero, F.; Kwag, K.; Liberati, E.G.; Mangia, M.; Kunnamo, I.; Cinquini, M.; et al. Implementing an evidence-based computerized decision support system linked to electronic health records to improve care for cancer patients: The ONCO-CODES study protocol for a randomized controlled trial. Implement. Sci. 2016, 11, 153. [CrossRef]

15. Maditinos, D.; Chatzoudes, D.; Sarigiannidis, L. Factors affecting e-business successful implementation. Int. J. Commer. Manag. 2014, 24, 300-320. [CrossRef]

16. Lee, Y.H.; Hsieh, Y.C.; Chen, Y.H. An investigation of employees' use of e-learning systems: Applying the technology acceptance model. Behav. Inf. Technol. 2013, 32, 173-189. [CrossRef]

17. Banerjee, P.M. Sustainable human capital: Product innovation and employee partnerships in technology firms. Cross Cult. Manag. Int. J. 2013, 20, 216-234. [CrossRef]

18. Lai, J.-Y.; Ong, C.-S. Assessing and managing employees for embracing change: A multiple-item scale to measure employee readiness for e-business. Technovation 2010, 30, 76-85. [CrossRef]

19. Kim, T.T.; Suh, Y.K.; Lee, G.; Choi, B.G. Modelling roles of task-technology fit and self-efficacy in hotel employees' usage behaviours of hotel information systems. Int. J. Tour. Res. 2010, 12, 709-725. [CrossRef]

20. Su, S.; Baird, K.; Blair, B. Employee organizational commitment: The influence of cultural and organizational factors in the Australian manufacturing industry. Int. J. Hum. Resour. Manag. 2009, 20, 2494-2516. [CrossRef]

21. Bilgihan, A. Gen Y customer loyalty in online shopping: An integrated model of trust, user experience and branding. Comput. Hum. Behav. 2016, 61, 103-113. [CrossRef]

22. Ashraf, A.R.; Thongpapanl, N.; Spyropoulou, S. The connection and disconnection between e-commerce businesses and their customers: Exploring the role of engagement, perceived usefulness, and perceived ease-of-use. Electron. Commer. Res. Appl. 2016, 20, 69-86. [CrossRef]

23. Puto, A.; Kościelniak, H. Analysis of Purchasing Behaviour of Polish e-customers. Procedia Comput. Sci. 2015, 65, 996-1005. [CrossRef] 
24. Davidavičienè, V.; Sabaitytė, J.; Davidavičius, S.; Potapov, M. Interaction with Customers Using Website Tools: Analysis of Lithuanian Manufacturing Sector. Procedia Soc. Behav. Sci. 2014, 110, 1262-1270. [CrossRef]

25. Kim, C.; Tao, W.; Shin, N.; Kim, K.-S. An empirical study of customers' perceptions of security and trust in e-payment systems. Electron. Commer. Res. Appl. 2010, 9, 84-95. [CrossRef]

26. Coussement, K.; Van den Poel, D. Integrating the voice of customers through call center emails into a decision support system for churn prediction. Inf. Manag. 2008, 45, 164-174. [CrossRef]

27. Chuang, S.-H. Facilitating the chain of market orientation to value co-creation: The mediating role of e-marketing adoption. J. Destin. Mark. Manag. 2018, 7, 39-49. [CrossRef]

28. Kim, H.-J.; Rha, J.-Y. Predicting the Drivers of the Intention to Use Mobile Learning in South Korea. Int. J. Interact. Mob. Technol. IJIM 2018, 12, 116. [CrossRef]

29. Okumus, B.; Ali, F.; Bilgihan, A.; Ozturk, A.B. Psychological factors influencing customers' acceptance of smartphone diet apps when ordering food at restaurants. Int. J. Hosp. Manag. 2018, 72, 67-77. [CrossRef]

30. Park, Y.B.; Yoon, S.J.; Yoo, J.S. Development of a knowledge-based intelligent decision support system for operational risk management of global supply chains. Eur. J. Ind. Eng. 2018, 12, 93-115. [CrossRef]

31. Roy, S.K.; Balaji, M.S.; Quazi, A.; Quaddus, M. Predictors of customer acceptance of and resistance to smart technologies in the retail sector. J. Retail. Consum. Serv. 2018, 42, 147-160. [CrossRef]

32. Salahshour Rad, M.; Nilashi, M.; Mohamed Dahlan, H. Information technology adoption: A review of the literature and classification. Univers. Access Inf. Soc. 2018, 17, 361-390. [CrossRef]

33. Singh, A.; Pandey, B. A New Intelligent Medical Decision Support System Based on Enhanced Hierarchical Clustering and Random Decision Forest for the Classification of Alcoholic Liver Damage, Primary Hepatoma, Liver Cirrhosis, and Cholelithiasis. J. Healthc. Eng. 2018, 2018, 1469043. [CrossRef]

34. Kaufmann, H.R.; Czinkota, M.R.; Zakrzewski, M. B2B and internal relationships and curative international marketing: A polish case study. Ind. Mark. Manag. 2015, 51, 69-78. [CrossRef]

35. Bach, M.P.; Čeljo, A.; Zoroja, J. Technology Acceptance Model for Business Intelligence Systems: Preliminary Research. Procedia Comput. Sci. 2016, 100, 995-1001. [CrossRef]

36. Chauhan, S.; Jaiswal, M. Determinants of acceptance of ERP software training in business schools: Empirical investigation using UTAUT model. Int. J. Manag. Educ. 2016, 14, 248-262. [CrossRef]

37. Hao, S.; Song, M. Technology-driven strategy and firm performance: Are strategic capabilities missing links? J. Bus. Res. 2016, 69, 751-759. [CrossRef]

38. Stock, R.; Gross, M. How Does Knowledge Workers' Social Technology Readiness Affect Their Innovative Work Behavior? In Proceedings of the 2016 49th Hawaii International Conference on System Sciences (HICSS), Koloa, HI, USA, 5-8 January 2016; pp. 2166-2175. [CrossRef]

39. Chang, J.-H.; Teng, C.-C. Intrinsic or extrinsic motivations for hospitality employees' creativity: The moderating role of organization-level regulatory focus. Int. J. Hosp. Manag. 2017, 60, 133-141. [CrossRef]

40. Jaradat, M.-I.R.; Imlawi, J.; Mashaqba, A. Investigating the Moderating Effects of Self-Efficacy, Age and Gender in the Context of Nursing Mobile Decision Support Systems Adoption: A Developing Country Perspective. Int. J. Interact. Mob. Technol. IJIM 2018, 12, 113. [CrossRef]

41. Park, N.; Rhoads, M.; Hou, J.; Lee, K. Understanding the acceptance of teleconferencing systems among employees: An extension of the technology acceptance model. Comput. Hum. Behav. 2014, 39, 118-127. [CrossRef]

42. Yoon, T.E.; Ghosh, B.; Bong-Keun, J. User Acceptance of Business Intelligence (BI) Application: Technology, Individual Difference, Social Influence, and Situational Constraints. In Proceedings of the 2014 47th Hawaii International Conference on System Sciences, Waikoloa, HI, USA, 6-9 January 2014; pp. 3758-3766. [CrossRef]

43. Sprague, R. A Framework for the Development of Decision Support Systems. MIS Q. 1980, 4, 1-25. [CrossRef]

44. Holsapple, C.W.; Whinston, A.B. Decision Support Systems: A Knowledge-Based Approach; West Publishing: St. Paul, MN, USA, 1996.

45. Power, D.J. A Brief History of Decision Support Systems. Available online: http://DSSResources.COM/ history/dsshistory.html (accessed on 20 August 2018).

46. Burstein, F.; Holsapple, C.W. Handbook on Decision Support Systems; Springer: Berlin, Germany, 2008.

47. Lucas, H.; Goh, J. Disruptive technology: How Kodak missed the digital photography revolution. J. Strateg. Inf. Syst. 2009, 18, 46-55. [CrossRef]

48. Erdoğmuş, N.; Esen, M. An Investigation of the Effects of Technology Readiness on Technology Acceptance in e-HRM. Procedia Soc. Behav. Sci. 2011, 24, 487-495. [CrossRef] 
49. Lin, J.; Hsieh, P. The influence of technology readiness on satisfaction and behavioral intentions toward self-service technologies. Comput. Hum. Behav. 2007, 23, 1597-1615. [CrossRef]

50. Rahayu, R.; Day, J. Determinant Factors of E-commerce Adoption by SMEs in Developing Country: Evidence from Indonesia. Procedia Soc. Behav. Sci. 2015, 195, 142-150. [CrossRef]

51. Schepers, J.; Wetzels, M. A meta-analysis of the technology acceptance model: Investigating subjective norm and moderation effects. Inf. Manag. 2007, 44, 90-103. [CrossRef]

52. Srivastava, A.P.; Dhar, R.L. Technology leadership and predicting travel agent performance. Tour. Manag. Perspect. 2016, 20, 77-86. [CrossRef]

53. Trainor, K.J.; Rapp, A.; Beitelspacher, L.S.; Schillewaert, N. Integrating information technology and marketing: An examination of the drivers and outcomes of e-Marketing capability. Ind. Mark. Manag. 2011, 40, 162-174. [CrossRef]

54. Ukpabi, D.C.; Karjaluoto, H. Consumers' acceptance of information and communications technology in tourism: A review. Telemat. Inform. 2017, 34, 618-644. [CrossRef]

55. Vize, R.; Coughlan, J.; Kennedy, A.; Ellis-Chadwick, F. Technology readiness in a B2B online retail context: An examination of antecedents and outcomes. Ind. Mark. Manag. 2013, 42, 909-918. [CrossRef]

56. Wang, W.-T.; Lai, Y.-J. Examining the adoption of KMS in organizations from an integrated perspective of technology, individual, and organization. Comput. Hum. Behav. 2014, 38, 55-67. [CrossRef]

57. Wu, B.; Chen, X. Continuance intention to use MOOCs: Integrating the technology acceptance model (TAM) and task technology fit (TTF) model. Comput. Hum. Behav. 2017, 67, 221-232. [CrossRef]

58. Lai, J.-Y.; Chen, W.-H. Measuring e-business dependability: The employee perspective. J. Syst. Softw. 2009, 82, 1046-1055. [CrossRef]

59. Parkes, A. The effect of task-individual-technology fit on user attitude and performance: An experimental investigation. Decis. Support Syst. 2013, 54, 997-1009. [CrossRef]

60. Fishbein, M.; Ajzen, I. Belief, Attitude, Intention, and Behavior: An Introduction to Theory and Research; Addison-Wesley: Reading, MA, USA, 1975.

61. Ajzen, I.; Fishbein, M. Understanding Attitudes and Predicting Social Behavior; Prentice Hall: Englewood Cliffs, NJ, USA, 1980.

62. Davis, F.D.; Bagozzi, R.P.; Warshaw, P.R. User acceptance of computer technology: A comparison of two theoretical models. Manag. Sci. 1989, 35, 985-986. [CrossRef]

63. Ahmed, F.; Qin, Y.; Aduamoah, M. Employee Readiness for Acceptance of Decision Support Systems as a New Technology in E-Business Environments; A Proposed Research Agend. In Proceedings of the 2018 7th International Conference on Industrial Technology and Management, Oxford, UK, 7-9 March 2018; p. 483.

64. Shropshire, J.; Warkentin, M.; Sharma, S. Personality, attitudes, and intentions: Predicting initial adoption of information security behavior. Comput. Secur. 2015, 49, 177-191. [CrossRef]

65. Bagozzi, R.P. The legacy of the technology acceptance model and a proposal for a paradigm shift. J. Assoc. Inf. Syst. 2007, 8, 244-254. [CrossRef]

66. Ifinedo, P. An Empirical Analysis of Factors Influencing Internet/E-Business Technologies Adoption by Smes in Canada. Int. J. Inf. Technol. Decis. Mak. 2011, 10, 731-766. [CrossRef]

67. Venkatesh, V.; Davis, F.D. A theoretical extension of the technology acceptance model: Four longitudinal field studies. Manag. Sci. 2000, 46, 186-205. [CrossRef]

68. Bueno, S.; Salmeron, J.L. TAM-based success modeling in ERP. Interact. Comp. 2008, 20, 515-523. [CrossRef]

69. Hsieh, J.-K.; Hsieh, Y.-C. Appealing to Internet-based freelance developers in smartphone application marketplaces. Int. J. Inf. Manag. 2013, 33, 308-317. [CrossRef]

70. Venkatesh, V.; Morris, M.; Davis, G.; Davis, F. User Acceptance of Information Technology: Toward a Unified View. Mis Q. 2003, 27, 425-478. [CrossRef]

71. Vroom, V. Work and Motivation; John Wiley: New York, NY, USA, 1964.

72. Atkin, D.; Chaudhry, A.; Chaudry, S.; Khandelwal, A.; Verhoogen, E. Organizational Barriers to Technology Adoption: Evidence from Soccer-Ball Producers in Pakistan. Q. J. Econ. 2017, 132, 1101-1164. [CrossRef]

73. Kuvaas, B.; Buch, R.; Weibel, A.; Dysvik, A.; Nerstad, C. Do intrinsic and extrinsic motivation relate differently to employee outcomes? J. Econ. Psychol. 2017, 61, 244-258. [CrossRef]

74. Costa, S.; Neves, P. Job insecurity and work outcomes: The role of psychological contract breach and positive psychological capital. Work Stress 2017, 31, 375-394. [CrossRef] 
75. Susarla, A.; Barua, A.; Whinston, A.B. Understanding the service component of application service provision: An empirical analysis of satisfaction with ASP services. MIS Q. 2003, 27, 91-123. [CrossRef]

76. Nam, T. Technology usage, expected job sustainability, and perceived job insecurity. Technol. Forecast. Soc. Chang. 2019, 138, 155-165. [CrossRef]

77. Ashford, S.J.; Lee, C.; Bobko, P. Content, causes, and consequences of job insecurity: A theory-based measure and substantive test. Acad. Manag. J. Acc. Educ. 1989, 32, 803-829.

78. Ruokolainen, M.; Mauno, S.; Cheng, T. Are the most dedicated nurses more vulnerable to job insecurity? Age-specific analyses on family-related outcomes. J. Nurs. Manag. 2014, 22, 1042-1053. [CrossRef]

79. Schumacher, D.; Schreurs, B.; Van Emmerik, H.; De Witte, H. Explaining the relation between job insecurity and employee outcomes during organizational change: A multiple group comparison. Hum. Resour. Manag. 2016, 55, 809-827. [CrossRef]

80. Bouzari, M.; Karatepe, O.M. Antecedents and outcomes of job insecurity among salespeople. Mark. Intell. Plan. 2018, 36, 290-302. [CrossRef]

81. Lastad, L.; Naswall, K.; Berntson, E.; Seddigh, A.; Sverke, M. The roles of shared perceptions of individual job insecurity and job insecurity climate for work- and health-related outcomes: A multilevel approach. Econ. Ind. Democr. 2018, 39, 422-438. [CrossRef]

82. Zhang, L.; Chen, L.; Teng, E.Y. When Does Job Insecurity Lead to Feedback-Seeking Behavior? The Counterintuitive Moderating Role of Perceived Organizational Support. Curr. Psychol. 2018, 37, 850-861.

83. Lin, X.; Chen, Z.; Ashford, S.; Lee, C.; Qian, J. A self-consistency motivation analysis of employee reactions to job insecurity: The roles of organization-based self-esteem and proactive personality. J. Bus. Res. 2018, 92, 168-178. [CrossRef]

84. Cheng, X.; Yin, G.; Azadegan, A.; Kolfschoten, G. Trust Evolvement in Hybrid Team Collaboration: A Longitudinal Case Study. Group Decis. Negot. 2016, 25, 267-288. [CrossRef]

85. Allred, C.R.; Fawcett, S.E.; Wallin, C.; Magnan, G.M. A Dynamic Collaboration Capability as a Source of Competitive Advantage. Decis. Sci. 2011, 42, 129-161. [CrossRef]

86. Sanders, N. An empirical study of the impact of e-business technologies on organizational collaboration and performance. J. Oper. Manag. 2007, 25, 1332-1347. [CrossRef]

87. Fawcett, S.E.; Wallin, C.; Allred, C.; Fawcett, A.M.; Magnan, G.M. Information technology as an enabler of supply chain collaboration: A dynamic-capabilities perspective. J. Supply Chain Manag. 2011, 47, 38-59. [CrossRef]

88. Azadegan, A.; Cheng, X.; Niederman, F.; Yin, G. Collaborative Requirements Elicitation in Facilitated Collaboration: Report from a Case Study. In Proceedings of the 46th Annual Hawaii International Conference on System Sciences, Maui, HI, USA, 7-10 January 2013; pp. 569-578. [CrossRef]

89. Alexiev, A.S.; Volberda, H.W.; Van den Bosch, F.A.J. Interorganizational collaboration and firm innovativeness: Unpacking the role of the organizational environment. J. Bus. Res. 2016, 69, 974-984. [CrossRef]

90. Agarwal, R.; Karahanna, E. Time flies when you're having fun: Cognitive absorption and beliefs about information technology usage. DSS Q. 2000, 24, 665-694. [CrossRef]

91. Iizuka, K.; Iizuka, Y.; Suematsu, C. E-Business Process Modeling Issues: From the Viewpoint of Inter-organizational Process Efficiency and Information Sharing. Procedia Comput. Sci. 2013, 22, 820-827. [CrossRef]

92. Holt, D.T.; Armenakis, A.A.; Feild, H.S.; Harris, S.G. Readiness for Organizational Change. J. Appl. Behav. Sci. 2016, 43, 232-255. [CrossRef]

93. Lee, J.Y.; Park, S.; Bakers, R. The moderating role of top management support on employees attitude. J. Manag. Organ. 2017. [CrossRef]

94. Prange, C.; Pinho, J.C. How personal and organizational drivers impact on SME international performance: The mediating role of organizational innovation. Int. Bus. Rev. 2017, 26, 1114-1123. [CrossRef]

95. Robinson, L.; Marshall, G.W.; Stamps, M.B. Sales force use of technology: Antecedents to technology acceptance. J. Bus. Res. 2005, 58, 1623-1631. [CrossRef]

96. Abdinnour-Helm, S.; Lengnick-Hall, M.L.; Lengnick-Hall, C.A. Pre-implementation attitudes and organizational readiness for implementing an Enterprise Resource Planning system. Eur. J. Oper. Res. 2003, 146, 258-273. [CrossRef]

97. Ahmad, M.H.; Ismail, S.; Rani, W.N.; Wahab, M.H. Trust in management, communication and organisational commitment: Factors influencing readiness for change management in organisation. AIP Conf. Proc. 2017, $1891,020019$. 
98. Shi, X.; Liao, Z. Inter-firm dependence, inter-firm trust, and operational performance: The mediating effect of e-business integration. Inf. Manag. 2015, 52, 943-950. [CrossRef]

99. Phong, L.; Hui, L.; Son, T.T. How leadership and trust in leaders foster employees' behavior toward knowledge sharing. Soc. Behav. Pers. 2018, 46, 705-720. [CrossRef]

100. Rhodes, C. Business Statistics; House of Commons Library: London, UK, 2017; pp. 2-5.

101. Hair, J.; Ringle, C.; Sarstedt, M. Partial Least Squares Structural Equation Modeling: Rigorous Applications, Better Results and Higher Acceptance. Long Range Plan. 2013, 46, 1-12. [CrossRef]

102. Hair, J.; Sarstedt, M.; Pieper, T.; Ringle, C. The Use of Partial Least Squares Structural Equation Modeling in Strategic Management Research: A Review of Past Practices and Recommendations for Future Applications. Long Range Plan. 2012, 45, 320-340. [CrossRef]

103. Marcoulides, G.A.; Saunders, C. PLS: A silver bullet? MIS Q. 2006, 30, III-IX. [CrossRef]

104. Wong, K.K. Partial Least Squares Structural Equation Modeling (PLS-SEM) Techniques Using SmartPLS. Mark. Bull. 2013, 24, 1-32.

105. Cohen, J. Statistical Power Analysis for the Behavioral Sciences, 2nd ed.; Lawrence Erlbaum Associates: Mahwah, NJ, USA, 1988.

106. Hair, J.F.; Hult, T.M.; Ringle, C.M.; Sarstedt, M. A Primer on Partial Least Squares Structural Equation Modeling (PLS-SEM); SAGE Publications Inc.: Thousand Oaks, CA, USA, 2014; p. 307.

107. Davis, F.D. A Technology Acceptance Model for Empirically Testing New End-User Information Systems: Theory and Results. Ph.D. Thesis, Massachusetts Institute of Technology, Cambridge, MA, USA, 1985.

108. Sarstedt, M.; Hair, J.F.; Ringle, C.M.; Thiele, K.O.; Gudergan, S.P. Estimation issues with PLS and CBSEM: Where the bias lies! J. Bus. Res. 2016, 69, 3998-4010. [CrossRef]

109. Ringle, C.M.; Wende, S.; Becker, J. SmartPLS 3; SmartPLS GmbH: Boenningstedt, Germany, 2015.

110. Venaik, S.; Midgley, D.F.; Devinney, T.M. Dual paths to performance: The impact of global pressures on MNC subsidiary conduct and performance. J. Int. Bus. Stud. 2005, 36, 655-675. [CrossRef]

111. Henseler, J.; Ringle, C.M.; Sarstedt, M. A new criterion for assessing discriminant validity in variance-based structural equation modeling. J. Acad. Mark. Sci. 2014, 43, 115-135. [CrossRef]

112. Hair, J.; Hollingsworth, C.L.; Randolph, A.B.; Chong, A.Y.L. An updated and expanded assessment of PLS-SEM in information systems research. Ind. Manag. Data Syst. 2017, 117, 442-458. [CrossRef]

113. Sarstedt, M.; Ringle, C.; Hair, J. PLS-SEM: Indeed a Silver Bullet. J. Mark. Theory Pract. 2011, 19, $139-152$.

114. Fornell, C.; Larcker, D.F. Structural equation models with unobservable variables and measurement error: Algebra and statistics. J. Mar. Res. 1981, 18, 382-388. [CrossRef]

115. Van der Wee, M.; Verbrugge, S.; Sadowski, B.; Driesse, M.; Pickavet, M. Identifying and quantifying the indirect benefits of broadband networks for e-government and e-business: A bottom-up approach. Telecommun. Policy 2015, 39, 176-191. [CrossRef]

116. Chin, W. The Partial Least Squares Approach to Structural Equation Modeling; Marcoulides, G.A., Ed.; Lawrence Erlbaum Associates: Mahwah, NJ, USA, 1998.

117. Becker, J.-M.; Klein, K.; Wetzels, M. Hierarchical Latent Variable Models in PLS-SEM: Guidelines for Using Reflective-Formative Type Models. Long Range Plan. 2012, 45, 359-394. [CrossRef]

118. Preacher, K.; Hayes, A. Asymptotic and resampling strategies for assessing and comparing indirect efects in multiple mediator models. Behav. Res. Methods 2008, 40, 879-891. [CrossRef]

119. Martinez-Martinez, D.; Herrera Madueno, J.; Larran Jorge, M.; Lechuga Sancho, M.P. The strategic nature of corporate social responsibility in SMEs: A multiple mediator analysis. Ind. Manag. Data Syst. 2017, 117, 2-31. [CrossRef]

120. Spears, J.; Barki, H. User participation in information systems security risk management. MIS Q. 2010, 34, 503-522. [CrossRef]

121. Goodhue, D.; Thompson, R. Task-technology fit and individual performance. MIS Q. 1995, 19, 213-236. [CrossRef]

122. Liu, Y.; Lee, Y.; Chen, A.N.K. Evaluating the effects of task-individual-technology fit in multi-DSS models context: A two-phase view. Decis. Support Syst. 2011, 51, 688-700. [CrossRef]

123. Lee, C.; Cheng, H.; Cheng, H. An empirical study of mobile commerce in insurance industry: Task-technology fit and individual differences. Decis. Support Syst. 2007, 43, 95-110. [CrossRef]

(C) 2019 by the authors. Licensee MDPI, Basel, Switzerland. This article is an open access article distributed under the terms and conditions of the Creative Commons Attribution (CC BY) license (http://creativecommons.org/licenses/by/4.0/). 